\title{
Regional Arctic sea ice variations as predictor for winter climate conditions
}

\author{
Torben Koenigk $^{1,2,3} \cdot$ Mihaela Caian $^{1} \cdot$ Grigory Nikulin $^{1} \cdot$ Semjon Schimanke $^{4}$
}

Received: 5 December 2014 / Accepted: 29 March 2015 / Published online: 14 April 2015

(c) The Author(s) 2015. This article is published with open access at Springerlink.com

\begin{abstract}
Seasonal prediction skill of winter mid and high northern latitudes climate from sea ice variations in eight different Arctic regions is analyzed using detrended ERAinterim data and satellite sea ice data for the period 19802013. We find significant correlations between ice areas in both September and November and winter sea level pressure, air temperature and precipitation. The prediction skill is improved when using November sea ice conditions as predictor compared to September. This is particularly true for predicting winter NAO-like patterns and blocking situations in the Euro-Atlantic area. We find that sea ice variations in Barents Sea seem to be most important for the sign of the following winter $\mathrm{NAO}$ - negative after low ice-but amplitude and extension of the patterns are modulated by Greenland and Labrador Seas ice areas. November ice variability in the Greenland Sea provides the best prediction skill for central and western European temperature and ice variations in the Laptev/East Siberian Seas have the largest impact on the blocking number in the Euro-Atlantic region. Over North America, prediction skill is largest using September ice areas from the Pacific Arctic sector as predictor. Composite analyses of high and low regional autumn ice conditions reveal that the atmospheric response is not entirely linear
\end{abstract}

Torben Koenigk

torben.koenigk@smhi.se

1 Rossby Centre, Swedish Meteorological and Hydrological Institute, 60176 Norrköping, Sweden

2 Department of Meteorology, Bert Bolin Centre for Climate Research, Stockholm University, 10654 Stockholm, Sweden

3 Swedish e-Science Research Centre, 10044 Stockholm, Sweden

4 Oceanography Research Unit, Swedish Meteorological and Hydrological Institute, 60176 Norrköping, Sweden suggesting changing predictive skill dependent on sign and amplitude of the anomaly. The results confirm the importance of realistic sea ice initial conditions for seasonal forecasts. However, correlations do seldom exceed 0.6 indicating that Arctic sea ice variations can only explain a part of winter climate variations in northern mid and high latitudes.

Keywords Arctic climate - Regional sea ice variations . Arctic-midlatitude interaction $\cdot$ Seasonal prediction

\section{Introduction}

Observations of the last decades indicate an ongoing climate change in the Arctic. The observed warming of near surface temperature in the Arctic is twice or more the rate of the global mean warming in the last decades (Stocker et al. 2013; Richter-Menge and Jeffries 2011). Ice-albedo feedback (Serreze et al. 2009; Screen and Simmonds 2010a, b), changes in clouds and water vapour (Graversen and Wang 2009; Liu et al. 2008), enhanced meridional energy transport in atmosphere (Graversen et al. 2008) and ocean (Koenigk and Brodeau 2014) and the vertical mixing in Arctic winter inversion (Bintanja et al. 2011) are likely contributors to this Arctic warming amplification. Snow cover on the Arctic continents is subject to extreme changes (Brown and Robinson 2011) and Arctic Ocean sea ice cover and volume have dramatically been reduced (Comiso et al. 2008; Devasthale et al. 2013).

Global and regional future model simulations indicate an accelerated Arctic climate change in the next decades (Chapman and Walsh 2007; Vavrus et al. 2012; Koenigk et al. 2011, 2013) with a potential total loss of Arctic sea ice in late summer until the middle of the twenty first century (Holland et al. 2010; Massonnet et al. 2012; Wang and Overland 2013). 
Sensitivity studies using climate models showed that ice anomalies in the Atlantic Arctic sector can affect the largescale atmospheric circulation (Magnusdottir et al. 2004; Alexander et al. 2004; Kvamstö et al. 2004; Koenigk et al. 2006). Recent studies based on both observational based data sets and model simulations indicated a connection between variations of late summer Arctic sea ice extent and winter mid-latitude conditions (Petoukhov and Semenov 2010; Francis et al. 2009; Yang and Christensen 2012; Overland and Wang 2010; Hopsch et al. 2012; Garcia-Serrano and Frankkignoul 2014). Most of these studies found that a reduction or negative anomaly in late summer sea ice extent leads to winter atmospheric circulation anomalies resembling the negative phase of the North Atlantic Oscillation (NAO) and thus to cold mid-latitude winters. However, controversy exists regarding the magnitude of these effects and the underlying mechanisms. Furthermore, most studies focused either on the entire northern hemispheric $(\mathrm{NH})$ ice extent or on the Barents Sea area, which is an area with extremely large ocean to atmosphere heat fluxes (Simonsen and Haugan 1996; Årthun and Schrum 2010), as predictors. It has not been shown yet that these indices are most promising for all mid and high latitude regions. Similar NH ice anomalies could occur due to very different spatial ice patterns-e.g. September 2007 and September 2012 ice distributions differed strongly (Devasthale et al. 2013) - leading to different anomalies of the related ocean to atmosphere heat fluxes. It has also been noticed that ice anomalies with opposite sign occur at the same time, e.g. positive ice anomalies in the Labrador Sea and negative anomalies in the Barents Sea during a positive NAO. Such ice distributions might lead to an amplification of the atmospheric response or could reduce the signal but in any case make the interpretation of the signal difficult.

Here, we systematically analyze the impact of autumn ice variations in eight different sub regions of the Arctic, one of them being the entire Arctic, on mid and high-latitude climate in the following winter using reanalysis data and satellite sea ice data. We discuss how the predictability depends on the region and the month used for prediction. The article is organized as follows: after the introduction, a description of the used data and methods will be given. Thereafter, we will present the results and possible mechanisms in Sects. 3 and 4, discuss caveats of this study in Sect. 5 and end with a conclusion.

\section{Data and methods}

\subsection{Data}

In this study, we use ERA-Interim reanalysis data for all atmospheric variables and sea ice concentration at $0.25^{\circ}$ resolution from the Ocean and Sea Ice Satellite Application Facility (OSI-SAF) data set (Eastwood et al. 2011). Differences exist between different satellite-derived sea ice data sets (Notz et al. 2013) and to our knowledge, the OSI-SAF sea ice data set has not been used so far in any of the existing studies on Arctic-mid latitude linkages. The ERA-Interim reanalysis is the latest in a series of reanalysis products from the European Centre for Medium Range Weather Forecasting (ECMWF, Dee et al. 2011). Reanalysis constitutes an optimal blend of model data and observations. ERA-Interim is based on cycle Cy31r2 of the ECMWF forecast model (Cy31r2) and is run at a spectral resolution of T255 with 60 hybrid-coordinate levels. It represents a newer generation of reanalysis relative to the ERA-40 reanalysis product from the ECMWF (Uppala et al. 2005), and many aspects of both the model and assimilation systems have been improved (see Dee et al. 2011 for a detailed account of model changes between ERA-40 and ERA-Interim).

However, one has to keep in mind that the Arctic is a data sparse region. Thus, to the extent that observations are not available in the Arctic, the data assimilation obviously provides less value, although effects from more southerly locations with better observational coverage should have a positive impact. A study by Jakobson et al. (2012) showed that the ERA-Interim reanalysis data is the most reliable reanalyses data set for the Arctic.

The main focus of our study is on the period 1980-2013. However, to further analyze the robustness of the results found in this study, we also used NCEP/NCAR reanalysis data (Kalnay et al. 1996) and sea ice data (Chapman and National Center for Atmospheric Research Staff 2013) for the period from 1960 onward.

\subsection{Methods}

We analyzed the relationship between Arctic sea ice variations in September, October and November and variations of atmospheric variables in the following winter season using lag-correlation and composite techniques. We performed these analyses for sea ice area variations in eight different Arctic regions (the entire Arctic and seven subregions, definition and abbreviations used in this study are given in Table 1).

The advantage of the composite pattern approach over correlation/regression analysis is that no assumption about the relationship between the variables is associated. Therefore nonlinear relationships can be detected as well. A disadvantage of the composite analysis is the subjective choice of the subsets and in our case, the small number of events. We thus used different criteria for the subsets ranging from ice anomalies exceeding 0.5 to 1 standard deviation. However, we will focus on the results using the 0.75 standard deviation criteria. 
Table 1 Arctic sub-regions used in this study

\begin{tabular}{lll}
\hline Region & Abbreviation & Area \\
\hline Northern Hemisphere & NH & $0-90 \mathrm{~N}, 0 \mathrm{E}-360 \mathrm{E}$ \\
Barents/Kara Seas & BAKA & $70-82 \mathrm{~N}, 15 \mathrm{E}-100 \mathrm{E}$ \\
Greenland Sea & GREEN & $50-75 \mathrm{~N}, 40 \mathrm{~W}-15 \mathrm{E}$ \\
Labrador Sea/Baffin Bay & LAB & $55-80 \mathrm{~N}, 70 \mathrm{~W}-40 \mathrm{~W}$ \\
Laptev/East Siberian Seas & LAPSIB & $70-82 \mathrm{~N}, 100 \mathrm{E}-180 \mathrm{E}$ \\
Chukchi/Bering Seas & CHUBER & $50-82 \mathrm{~N}, 170 \mathrm{E}-160 \mathrm{~W}$ \\
Beaufort Sea & BEAU & $70-82 \mathrm{~N}, 160 \mathrm{~W}-90 \mathrm{~W}$ \\
Central Arctic & CARC & $80-90 \mathrm{~N}, 0-360 \mathrm{E}$ \\
\hline
\end{tabular}

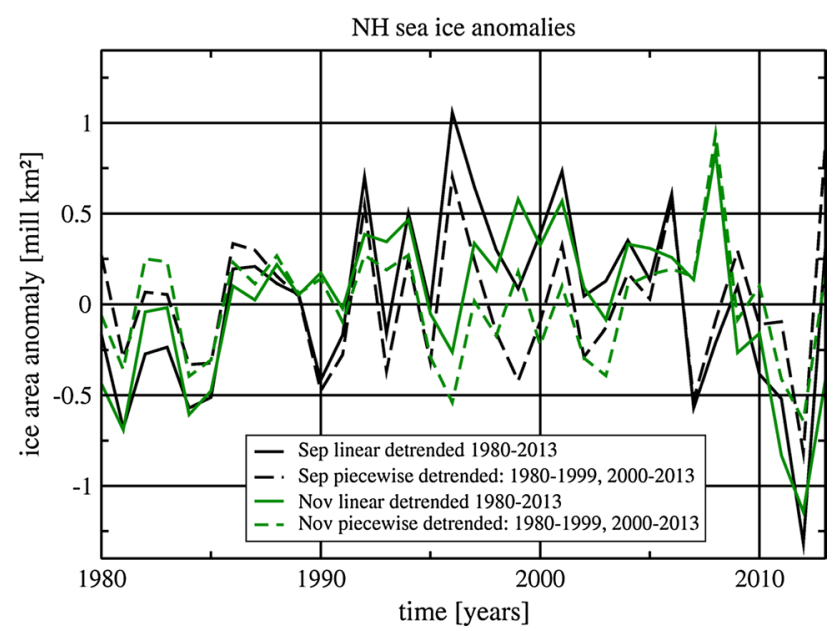

Fig. 1 September (black) and November (green) Northern Hemisphere sea ice area anomalies after linear detrending over the entire period (solid) and piecewise detrending over the periods 1980-1999 and 2000-2013 (dashed)

Since the aim of this study is to investigate seasonal predictability, all data have been detrended before applying statistical methods. Detrending of relatively short time series, which might even be subject of decadal or longer natural variations, is a difficult task. We tested two different ways of detrending. The first approach was to subtract the linear trend over the entire period (19802013) as done in Hopsch et al. (2012). The second one was to subtract the linear trend separately for the periods 1980-1999 and 2000-2013. The reason for this is that the trend of sea ice area in the Arctic seems to be nonlinear and several sub-regions show an accelerated negative ice trend after 1999 (Figs. 1, 2). We will focus on results using the second approach since a linear detrending over the entire time period leads in a few sub-regions to a large number of positive anomalies in the middle of the time series (Fig. 1), which would affect both calculations of correlations and composites. Although we cannot totally exclude the possibility that large multi-decadal variations lead to high ice values exactly in the middle of the ERA-interim period, we consider this as unlikely. However, the main conclusions from this study do not change when using the first approach, although the relationship between sea ice anomalies and following atmospheric response are somewhat different in a few regions. In general, we find a slightly reduced signal using our second approach. This might indicate that subtracting the linear trend over the entire 1980-2013 period could lead to overconfidence of the predictability arising from sea ice variations.

The significance at each grid point has been calculated using a student $t$ test (von Storch and Zwiers 1999). Assuming 34 degrees of freedom and a normal distribution, correlations are significant at the $95 \%$ level, if the correlation coefficient reaches 0.36 ( 0.30 for $90 \%$ significance). Note, that this assumption is not entirely correct for all grid points. While the autocorrelation at a lag of 1 year is very small for the sea ice areas and sea level pressure (SLP), autocorrelations of air temperature reach up to 0.5 over some ocean regions. In these regions, the effective numbers of freedom is reduced and thus the correlations coefficient needed to reach $95 \%$ significance is increased. The assumption of a close to normal distribution is commonly made for SLP, air temperature and ice area variations; no clear limitation is existing at the lower or upper end as it is the case for precipitation or sea surface temperature distribution. For simplicity and due to the spatial limitations of the areas with larger autocorrelations, we will mark in our figures all values exceeding a correlation coefficient of 0.36 as significant.

For the composites we assumed that the sample is distributed as $\mathrm{N}\left(\mathrm{a}, \sigma^{2}\right)$ with unknown variance $\sigma^{2}$. We calculated if the mean of the sample a is different from zero, using a Student $t$ test.

\section{Results}

The Arctic sea ice area shows large interannual variations and a negative trend over the 1980-2013 period (Fig. 2). The reduction is accelerated since year 2000 both in September and November. The sea ice area variations and trends differ substantially among different Arctic sub-regions.

The September NH ice area is highly correlated with ice area variations in the Laptev/East Siberian Seas (LAPSIB), Chukchi/Bering Seas (CHUBER) and Beaufort Sea (BEAU) (Table 2, upper right). These areas show a similar temporal evolution of the trend (Fig. 2). Other significant correlations among ice areas occur between Barents/Kara Seas (BAKA)-Central Arctic (CARC), LAPSIB-CHUBER and CHUBER-BEAU. Adjacent regions tend to be slightly better correlated than regions far away from each 
Fig. 2 September (black) and November (green) ice area in $\left(10^{12} \mathrm{~m}^{2}\right)$ in all sub regions for the period 1980-2013
Table 2 Correlations among ice areas in the Arctic subregions in September (upper row of each box, italic) and correlations among November Arctic sub-regions ice area variations (lower row of each box) (a) $\mathrm{NH}, 0-90 \mathrm{~N}, 0-360 \mathrm{E}$
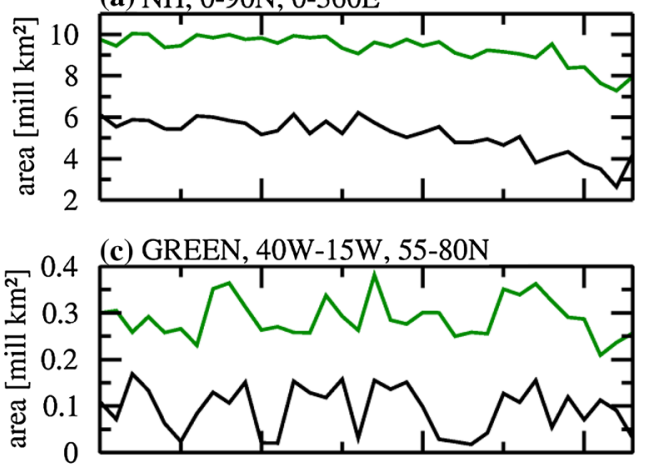

(e) LAPSIB, 100-180E, 70-82N

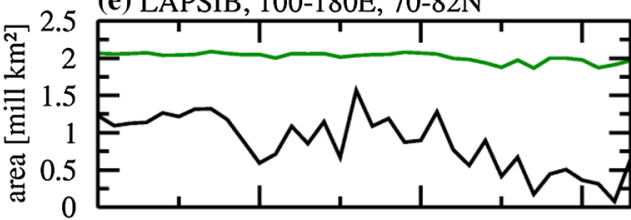

(g) BEAU, 160W-90W, $70-82 \mathrm{~N}$

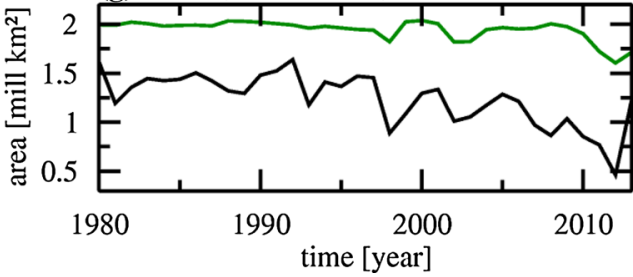

(b) BAKA, 70-82N, 15-100E
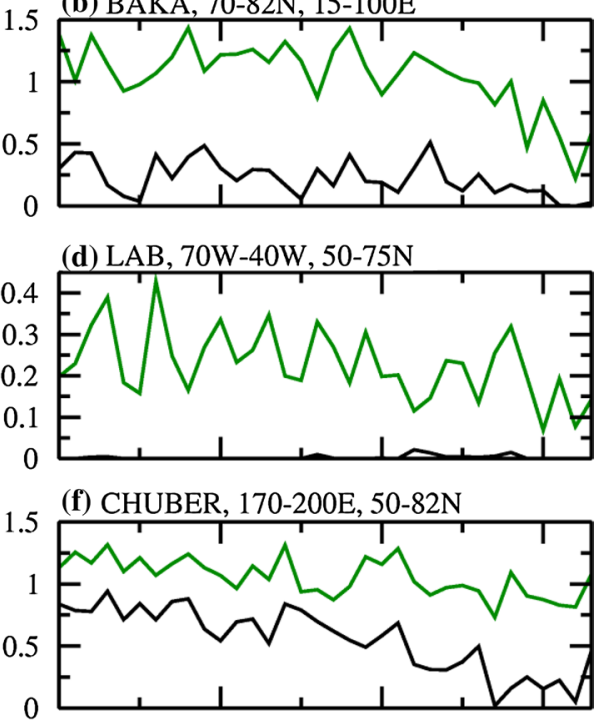

(h) CARC, 0-360E, 80-90N

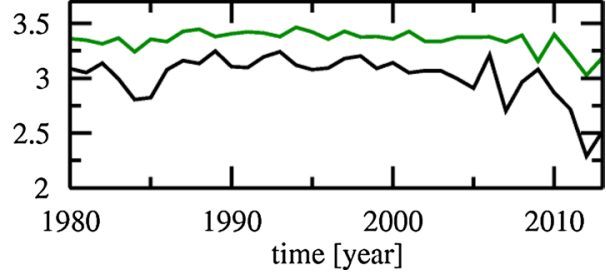

\begin{tabular}{|c|c|c|c|c|c|c|c|c|}
\hline $\begin{array}{l}\text { Sep } \\
\text { Nov }\end{array}$ & $\mathrm{NH}$ & BAKA & GREEN & LAB & LAPSIB & CHUBER & BEAU & CARC \\
\hline NH & $\begin{array}{l}1 \\
1\end{array}$ & $\begin{array}{l}0.15 \\
\mathbf{0 . 5 5}\end{array}$ & $\begin{array}{l}0.12 \\
\mathbf{0 . 4 0}\end{array}$ & $\begin{array}{l}-0.11 \\
\mathbf{0 . 5 0}\end{array}$ & $\begin{array}{l}0.70 \\
0.24\end{array}$ & $\begin{array}{l}\mathbf{0 . 6 2} \\
0.25\end{array}$ & $\begin{array}{l}0.59 \\
0.64\end{array}$ & $\begin{array}{l}0.49 \\
0.63\end{array}$ \\
\hline BAKA & & $\begin{array}{l}1 \\
1\end{array}$ & $\begin{array}{l}-0.01 \\
0.27\end{array}$ & $\begin{array}{l}0.28 \\
-0.10\end{array}$ & $\begin{array}{l}-0.13 \\
-0.01\end{array}$ & $\begin{array}{l}-0.32 \\
-0.06\end{array}$ & $\begin{array}{l}-0.36 \\
0.01\end{array}$ & $\begin{array}{l}0.61 \\
0.64\end{array}$ \\
\hline GREEN & & & $\begin{array}{l}1 \\
1\end{array}$ & $\begin{array}{l}-0.35 \\
-0.08\end{array}$ & $\begin{array}{l}-0.12 \\
-0.02\end{array}$ & $\begin{array}{l}0.07 \\
0.04\end{array}$ & $\begin{array}{l}-0.10 \\
\mathbf{0 . 4 1}\end{array}$ & $\begin{array}{l}0.26 \\
\mathbf{0 . 4 9}\end{array}$ \\
\hline LAB & & & & $\begin{array}{l}1 \\
1\end{array}$ & $\begin{array}{l}-0.15 \\
-0.05\end{array}$ & $\begin{array}{l}-0.26 \\
-0.07\end{array}$ & $\begin{array}{l}-0.17 \\
\mathbf{0 . 4 0}\end{array}$ & $\begin{array}{l}-0.07 \\
0.05\end{array}$ \\
\hline LAPSIB & & & & & $\begin{array}{l}1 \\
1\end{array}$ & $\begin{array}{l}0.56 \\
0.56\end{array}$ & $\begin{array}{l}0.19 \\
0.11\end{array}$ & $\begin{array}{l}0.12 \\
-0.01\end{array}$ \\
\hline CHUBER & & & & & & $\begin{array}{l}1 \\
1\end{array}$ & $\begin{array}{l}0.39 \\
0.00\end{array}$ & $\begin{array}{l}0.19 \\
-0.02\end{array}$ \\
\hline BEAU & & & & & & & $\begin{array}{l}1 \\
1\end{array}$ & $\begin{array}{l}-0.06 \\
\mathbf{0 . 4 8}\end{array}$ \\
\hline CARC & & & & & & & & $\begin{array}{l}1 \\
1\end{array}$ \\
\hline
\end{tabular}

All values are detrended before correlation. Significant correlations exceeding the $95 \%$-level are marked bold

other. Note, that the CARC area overlaps somewhat with the surrounding areas and that there is almost no sea ice in the Labrador Sea region (LAB) in September.

In fall, refreezing of sea ice restarts, which changes the correlations among regions. In November, the NH ice area is not any more significantly correlated with LAPSIB and
CHUBER. Correlation to BEAU ice area is still high and correlations with Atlantic sector ice areas (BAKA, GREEN, LAB) are now significant. Ice area in CARC shows similar correlations with the other subareas as $\mathrm{NH}$ and also ice area in BEAU is significantly positively correlated to the sea ice areas in GREEN and LAB. 

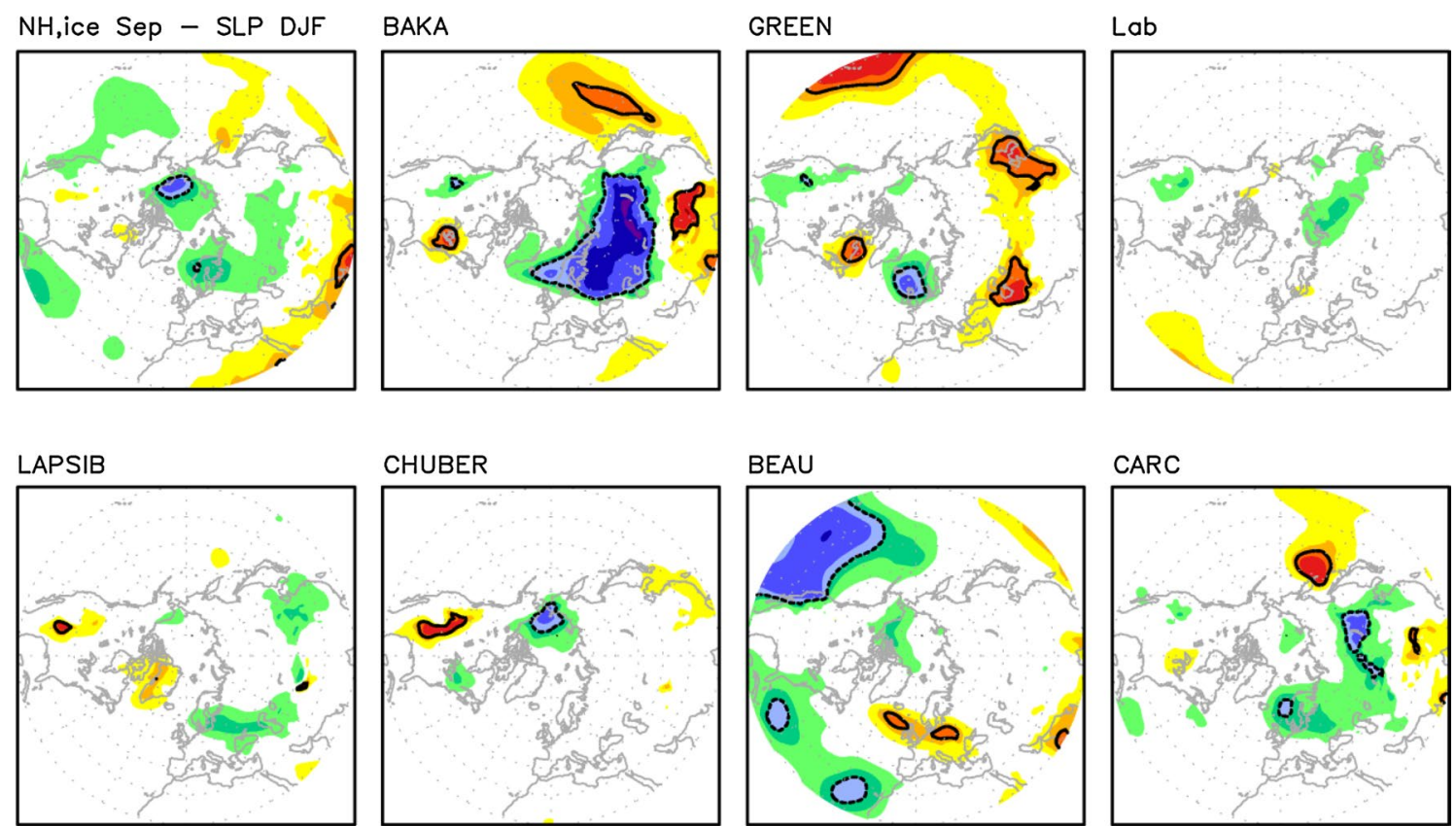

CHUBER
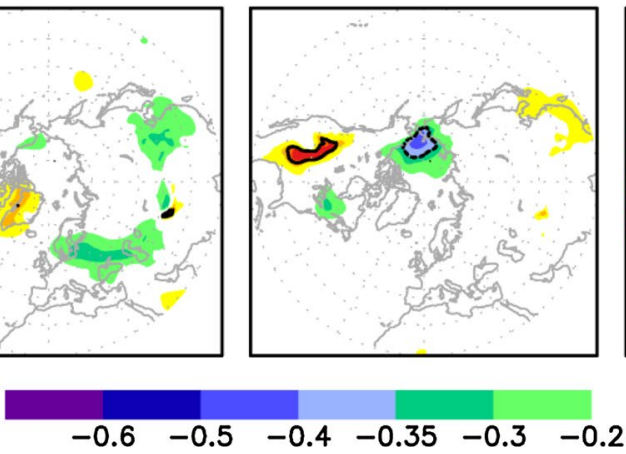

\section{BEAU}

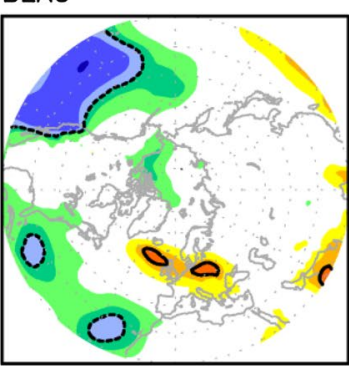

CARC

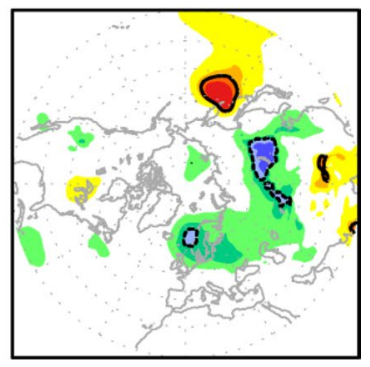

0.2 $\begin{array}{lll}0.3 & 0.35 & 0.4\end{array}$
$0.5 \quad 0.6$

Fig. 3 Correlation between September sea ice area and SLP in the following winter (DJF) in the period 1980-2013. All data are detrended. Black lines indicate significance at the $95 \%$ level

In Sect. 3.1, we analyze the linear relationship between sea ice anomalies in September and November and mid and high latitude climate in the following winter by performing lagged correlation analyses. Section 3.2 analyzes composites of anomalously high and low sea ice areas to extract non-linear signals in the atmospheric response.

\subsection{Linear response of winter atmosphere to autumn sea ice anomalies}

\subsubsection{Sea level pressure}

Figure 3 shows the lag-correlation between September ice area anomalies in the Arctic sub-regions and winter mean (December, January, February, DJF) SLP anomalies. The SLP response is largest after sea ice anomalies in BAKA and BEAU. After large ice extents in BAKA, significantly negative SLP anomalies occur from Iceland across Scandinavia toward Siberia with maximum correlation coefficients of about -0.6 . At the same time, a band with partly significant high pressure anomalies occurs further to the south, particularly over Central Asia and the North Pacific. This response is substantially different to the NAO like response, which has been reported in former studies (Hopsch et al. 2012; Petoukhov and Semenov 2010). However, subtracting the linear trend over the entire period 1980-2013, we get a SLP-response, which could be characterized as a slightly eastward shifted NAO pattern (not shown).

After ice anomalies in the Beaufort Sea, a significant signal occurs over the northeastern Pacific and over the subtropical Atlantic. A positive correlation can be seen over parts of western and central Europe.

The correlation of SLP with ice anomalies in the Greenland Sea is significantly negative over northwestern Europe and positive over the Caspian Sea area, northern China and northeastern Canada. Interestingly, the areas with positive correlation over Asian regions are exactly those areas where the positive correlation of SLP with sea ice in BAKA is low. Also subtropical Pacific areas are significantly positively correlated to the Greenland ice area.

The linear relation between winter SLP and September ice in the other Arctic areas is predominantly small. However, CARC and NH correlations versus SLP show similar correlation patterns over Eurasia as BAKA but smaller values. The similarities for CARC and BAKA might be explained by the fact that September ice areas in BAKA and CARC are significantly correlated. However, the correlation between $\mathrm{NH}$ and BAKA ice areas is small.

In contrast to a recent study by Garcia-Serrano and Frankkignoul (2014) who found similar predictive skills for the Euro-Atlantic region using sea ice in September, October and November, Fig. 4 shows increased correlations between November sea ice areas and winter SLP. In 

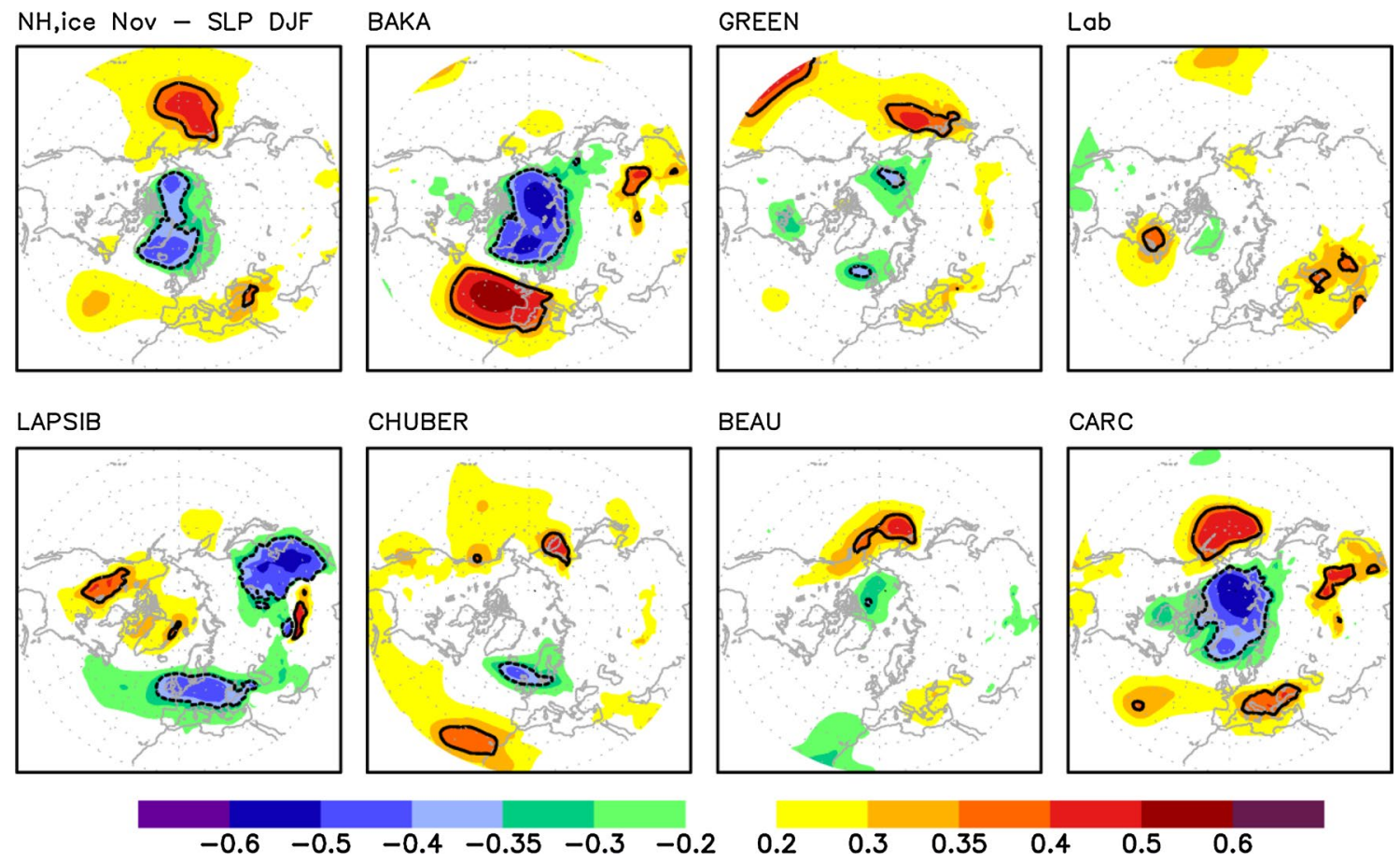

BEAU

CARC
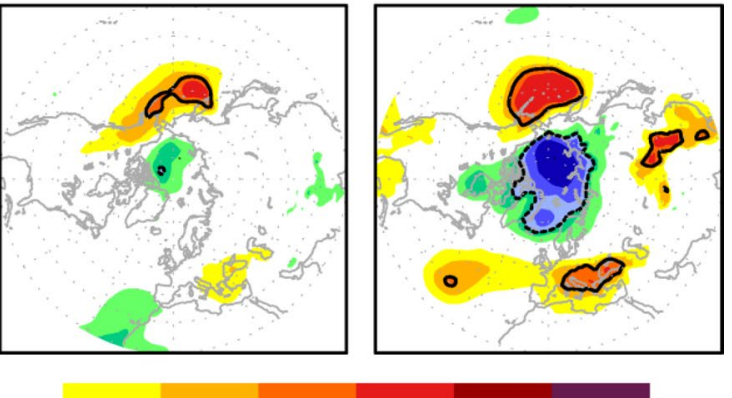

$\begin{array}{llllll}-0.6 & -0.5 & -0.4 & -0.35 & -0.3 & -0.2\end{array}$

0.2

$\begin{array}{lll}0.3 & 0.35 & 0.4\end{array}$

$0.5 \quad 0.6$

Fig. 4 The same as Fig. 3 but for November sea ice area

particular, we see now a strongly pronounced NAO-like pattern following BAKA ice anomalies (positive NAO after positive ice anomalies). This agrees quite well with a recent study by Scaife et al. (2014) who found that initialization of sea ice in the Kara Sea is important for predicting the NAO of the following winter. We find similar-but less pronounced-correlation patterns between SLP and preceding ice in NH and CARC. November ice area in LAPSIB is significantly negatively correlated with winter SLP over Europe and eastern Asia and positively correlated over northern Canada. While the correlation pattern between SLP and GREEN ice area remains relatively similar in September and November, the high negative correlation of September BEAU ice and winter SLP over the eastern North Pacific disappears using November sea ice. This might be caused by strongly reduced sea ice variations in the Beaufort Sea in November compared to September (Fig. 2).

\subsubsection{Blocking}

Intensive and long lasting blockings, occurring in the Euro-Atlantic sector, are in winter related to extremely cold conditions while in summer they are associated with severe heat waves, for example the heat wave in summer 2003 over central Europe (Schär et al. 2004) and in summer 2010 over the central part of Russia (Barriopedro et al. 2011). Impacts of such intensive blocking events are also felt outside of the European region as for example heavy flooding in Pakistan in summer 2010 caused by the same long-lasting blocking (about 40 days) over central Russia (Lau and Kim 2012). Although, mechanisms of blocking formation in the Euro-Atlantic sector have been intensively studied during the last few decades (e.g. Nakamura et al. 1997; Orsolini and Nikulin 2006), seasonal forecasting of blocking events is still a challenging task.

In this study, blocking statistics are estimated following the methodology of Tibaldi and Molteni (1990) with modifications introduced by Barriopedro et al. (2006). First, all blocked longitudes are identified for each day using two geopotential height gradients $\left(40^{\circ}-60^{\circ} \mathrm{N}\right.$ and $\left.60-80^{\circ} \mathrm{N}\right)$ at the $500 \mathrm{hPa}$ level as the main criteria and then temporal and spatial filters are applied to isolate only blocking events, which last more than 5 days and have spatial extensions of more than $10^{\circ}$ of longitudes. Using the temporally- and spatially-filtered blocked longitudes and days we estimate a number of single blocking events over the Euro-Atlantic sector $\left(60^{\circ} \mathrm{W}-60^{\circ} \mathrm{E}\right)$.

Figure 5 shows the lag correlation between sea ice concentration in September and November and blocking number in the following winter. In September, in most areas, the correlations are relatively low and not significant. The same is true for October (not shown). Only sea ice concentration in the East Siberian and Chukchi Seas show significant impact on the blocking number; reduced ice concentration in September in this region is related to more blockings 
Fig. 5 Correlation between September (left) and November (right) sea ice concentration and the following winter (DJF) blocking number in the EuroAtlantic area (left). All data are detrended. Black lines indicate significance at the $95 \%$ level
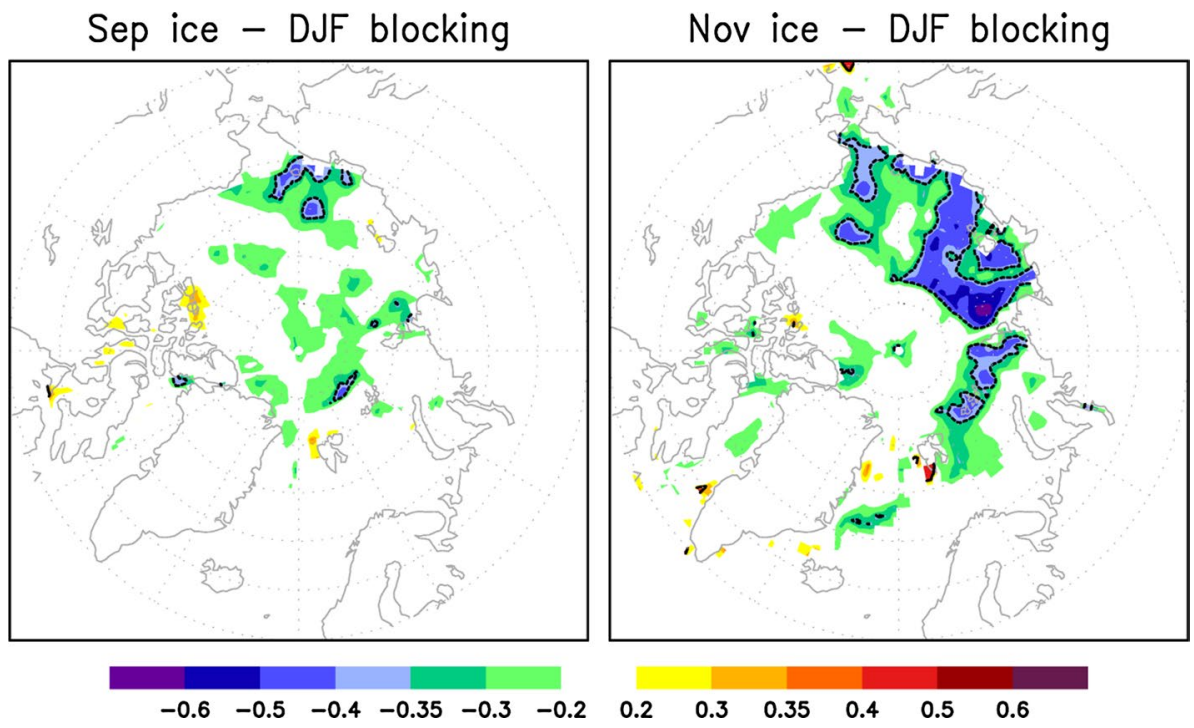

BAKA

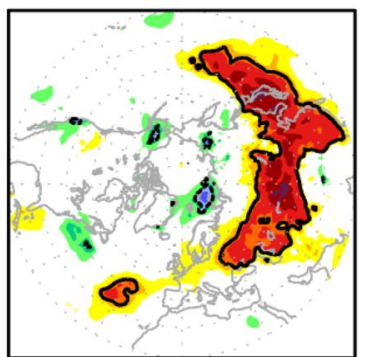

CHUBER

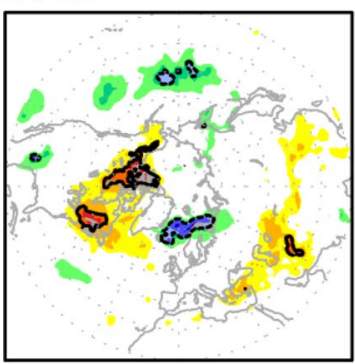

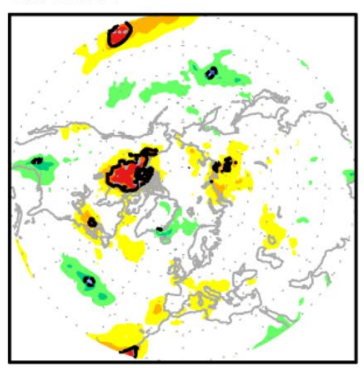

4
GREEN

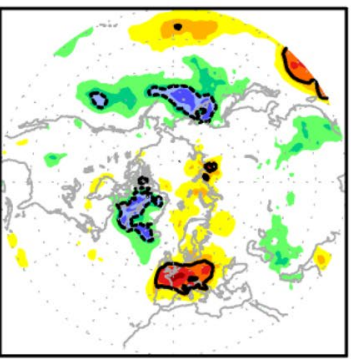

BEAU

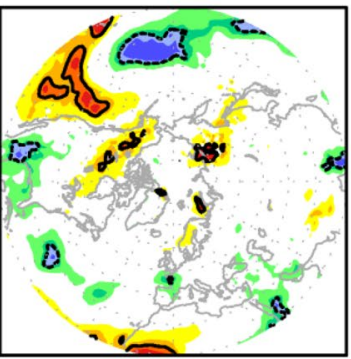

Lab

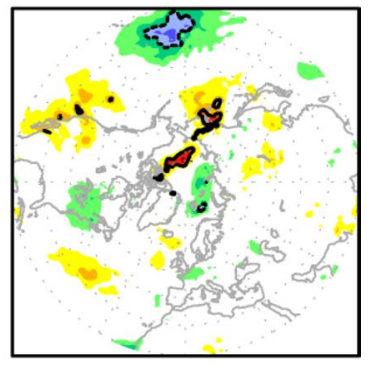

CARC

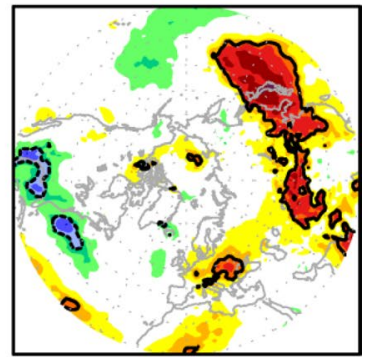

$\begin{array}{llllll}-0.6 & -0.5 & -0.4 & -0.35 & -0.3 & -0.2\end{array}$

0.2

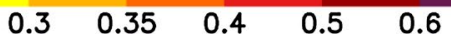

Fig. 6 Correlation between September sea ice area and T2m in the following winter (DJF) in the period 1980-2013. All data are detrended. Black lines indicate significance at the $95 \%$ level

over the Euro-Atlantic area in the following winter. When approaching the winter, in November, sea ice concentration is substantially stronger correlated with the winter blocking number over the Euro-Atlantic area. Along almost the entire Siberian coast, negative ice concentration anomalies lead an increased number of winter blockings. Comparing to Fig. 4, we find that the winter SLP response to reduced ice in these areas resembles a winter blocking pattern over the Euro-Atlantic region.

\subsubsection{Air temperature}

The linear relationship between winter $\mathrm{T} 2 \mathrm{~m}$ and preceding autumn sea ice area anomalies are shown in Figs. 6 and 7. The T2m signal is at least partly dominated by the SLP response to ice anomalies. September BAKA ice area is significantly positively correlated to winter $\mathrm{T} 2 \mathrm{~m}$ over large parts of mid-latitudes of eastern Europe and Asia. This agrees well with findings from previous studies (Petoukhov 

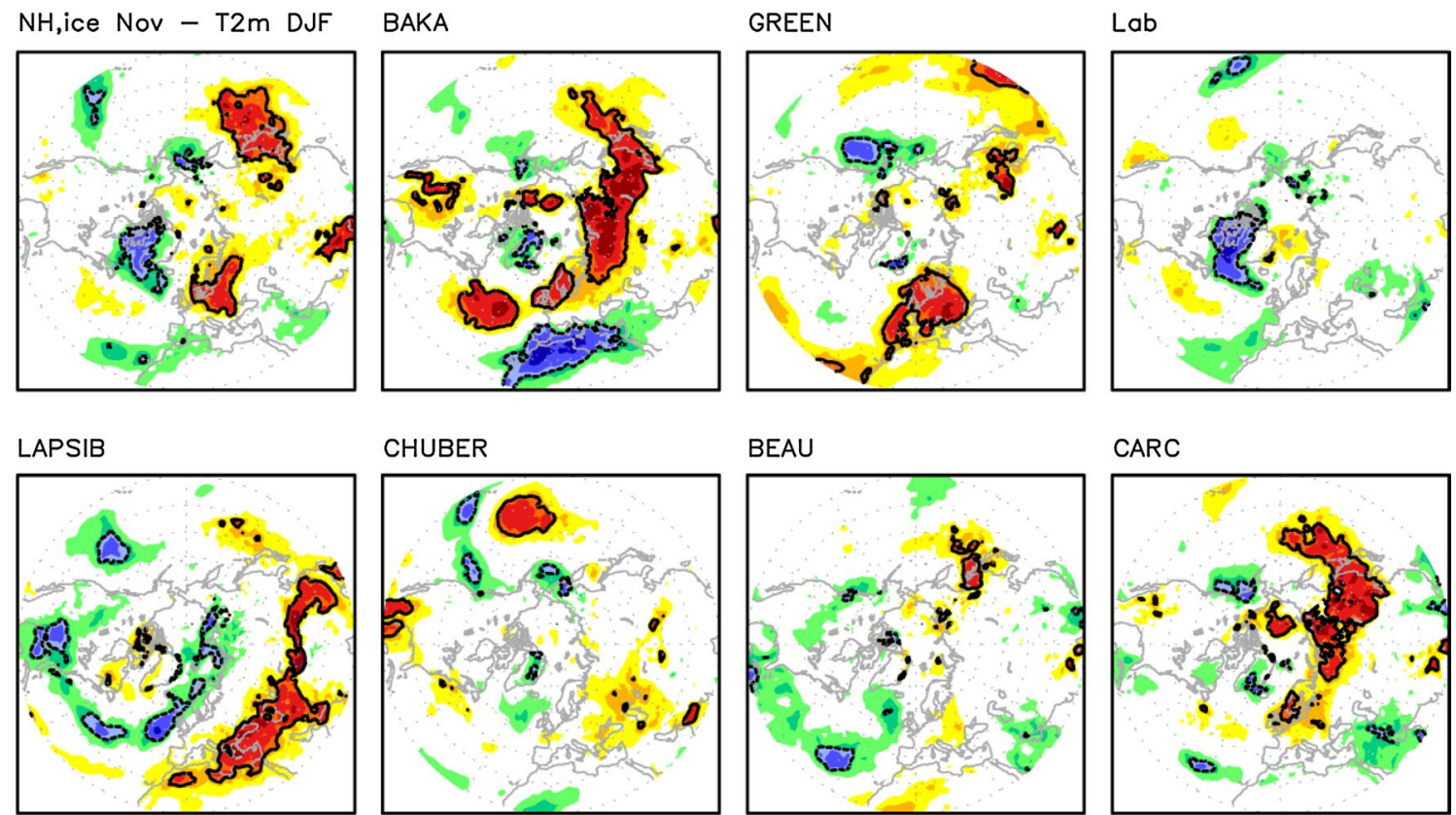

CHUBER

BEAU

CARC
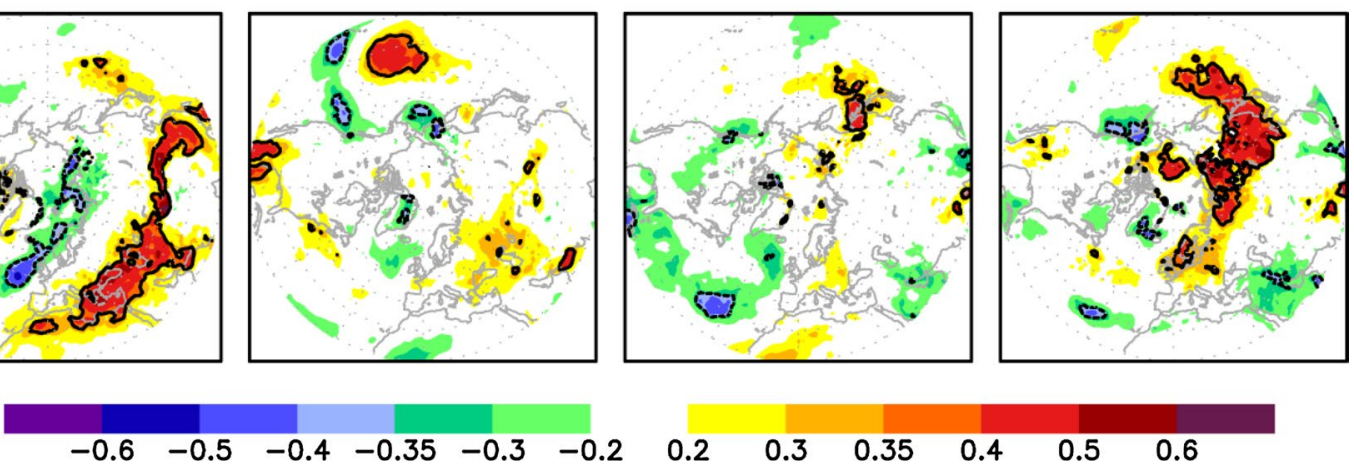

0.2

0.3
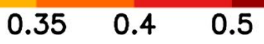

0.6

Fig. 7 The same as Fig. 6 but for November sea ice area

and Semenov 2010; Yang and Christensen 2012). This response is very likely caused by advection of warm air from the west into these regions (compare Fig. 3). Positive correlations with $\mathrm{T} 2 \mathrm{~m}$ over Asia can also be found for $\mathrm{NH}$ and CARC ice areas; however, as for SLP, the correlations are smaller and only locally significant compared to BAKA ice area. Instead, significant correlations occur over parts of the United States and over northern Canada (with NH ice area). The so called "warm Arctic-cold mid-latitude pattern" after low September ice area, which has been reported in several other recent studies (Overland et al. 2011; Inoue et al. 2012; Petoukhov and Semenov 2010) is not very pronounced in our analysis although low September BAKA ice area is also followed by warm temperatures in the BAKA area itself. One reason for this might be that we use detrended data while many other studies analyzed differences between the last decade with strongly reduced $\mathrm{NH}$ ice and the decades before.

September Greenland ice area is significantly positively correlated with winter T2m over western and central Europe and negatively correlated over Labrador and Irminger Seas and parts of Greenland as well as over the northern North Pacific.

Predictive skill for the North American land areas is mainly provided by ice variability in the Pacific Arctic sector: Ice variations in BEAU provide significant predictability over parts of Alaska and Canada and over the North Pacific. LAPSIB ice area is positively correlated with T2m over large areas in Canada. September ice in CHUBER shows significantly positive correlations with winter $\mathrm{T} 2 \mathrm{~m}$ over northern Canada.

Similar to SLP, the T2m signal to November ice anomalies in a number of Arctic sub-regions is getting larger compared to September, particularly over the AtlanticEurope-Asia area (Fig. 7). The NAO like pattern related to November ice anomalies in BAKA, NH and CARC leads to positive correlations with winter $\mathrm{T} 2 \mathrm{~m}$ over large parts of northern Europe and Siberia. The area of positive correlations moves northward compared to the September correlations (compare Fig. 6). Over southern Europe, negative correlations occur, most pronounced for BAKA sea ice. BAKA ice is also positively correlated to $\mathrm{T} 2 \mathrm{~m}$ over the central United States and $\mathrm{NH}$ ice area is significantly correlated to T2m over an area from the Labrador Sea/Baffin Bay towards northeastern Canada.

High positive correlations are found between November GREEN ice area and winter T2m over large parts of Europe. Significantly negative correlations with LAPSIB ice occur in a band from North America across the North Atlantic and northwestern Europe to Kara and Laptev Sea. At the same time, positive correlations can be seen from southeastern Europe across Asia to northern China and the Pacific Ocean. November sea ice area variations in BEAU and CHUBER do not provide improved predictions compared to September. Sea ice in LAB is locally highly negatively correlated with winter $\mathrm{T} 2 \mathrm{~m}$ over the $\mathrm{LAB}$ area itself and surroundings. 

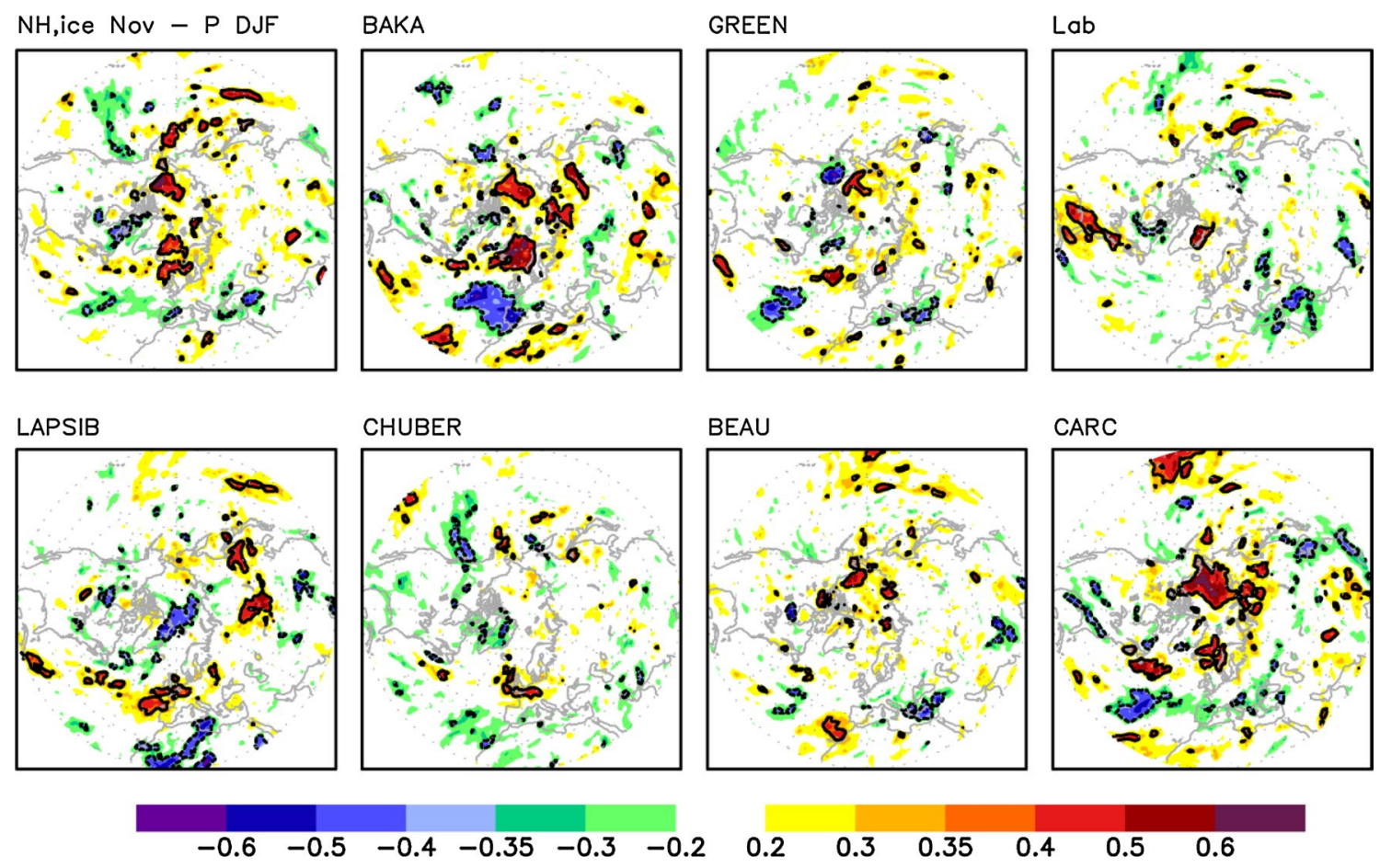

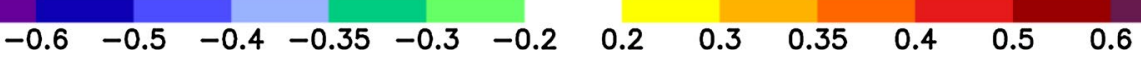

Fig. 8 Correlation between November sea ice area and precipitation in the following winter (DJF) in the period 1980-2013. All data are detrended. Black lines indicate significance at the $95 \%$ level

\subsubsection{Precipitation}

The impact of November sea ice variation on winter precipitation $(\mathrm{P})$ is shown in Fig. 8. The pattern is more scattered and significant areas are smaller as for T2m and SLP. In general, the response of $\mathrm{P}$ over land areas away from the coastlines is quite small. Here, we will only mention the largest areas with significant correlations: Correlations versus BAKA, NH and CARC ice areas show positive values over the Nordic Seas and parts of northern Europe and negative values over southwestern Europe and adjacent North Atlantic areas. Over the Arctic Ocean and parts of the Siberian coast, $\mathrm{P}$ and preceding ice areas are positively correlated. After positive ice anomalies in CHUBER and LAPSIB, western and central Europe experience more $\mathrm{P}$ as usual and northern Africa below normal P. Ice variations in the Labrador Sea affect southeastern Europe and the Middle East and the east coast of North America.

\subsection{Non-linear atmospheric response to autumn ice anomalies}

It is still an unsolved question whether the atmospheric response to sea ice anomalies is linear. Liptak and Strong (2014) showed, performing sensitivity experiments with the atmosphere model CAM, a similar response of the NAO to both negative and positive sea ice anomalies in the Barents
Sea. Caian et al. (submitted) using ERA-interim data indicated an increasingly nonlinear SLP-pattern for very high and low NAO states. These results indicate that the predictability might depend on the state of the regional or pan-Arctic ice anomalies. In the following, we discuss the response of winter SLP and T2m to positive and negative autumn sea ice anomalies. We will focus on the response to November as November ice variations showed the highest predictive skill using correlation analysis in Sect. 3.1. As before, detrended values will be used.

\subsubsection{Sea level pressure}

Figure 9 shows the winter SLP anomalies after preceding November sea ice anomalies in the different Arctic regions exceeding \pm 0.75 standard deviation.

The SLP response to high ice in all areas except for LAB, LAPSIB and BEAU is dominated by low SLP over the Nordic Seas and Arctic Ocean and higher SLP over the mid-latitude Euro-Atlantic and Pacific areas. The exact position and extension of the anomalies vary depending on the predictor sub-region. The SLP anomalies reach up to $\pm 4 \mathrm{hPa}$ in several areas but due to the small number of cases and high atmospheric variability in winter, the $95 \%$ significance level is not reached in all these areas with large response. The most significant SLP response appears after high ice area in CHUBER. The relatively similar response 
(a) SLP, NH 0.75 std

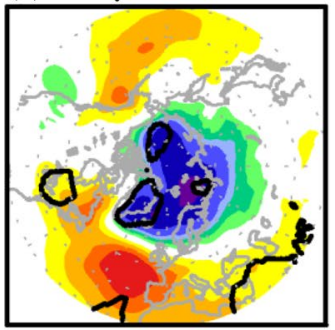

(e) LAPSIB 0.75 std

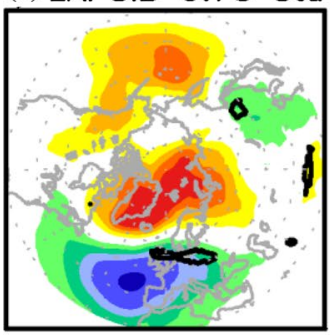

(i) $\mathrm{NH}-0.75 \mathrm{std}$

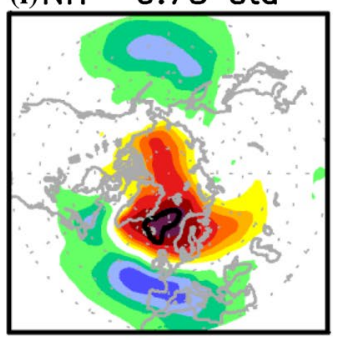

(m) LAPSIB -0.75 std

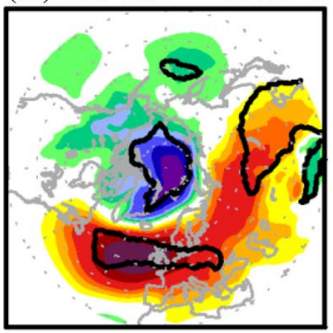

(b) BAKA 0.75 std

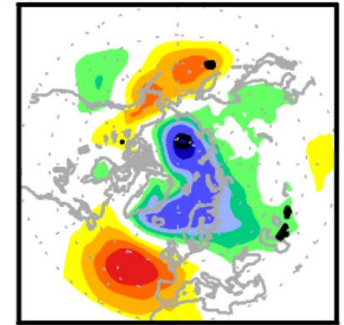

(f) CHUBER 0.75 std

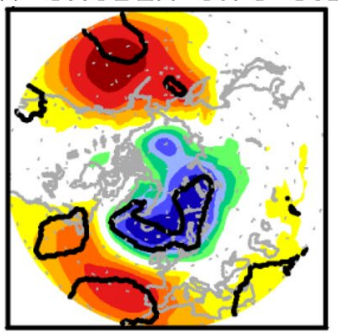

(j) BAKA -0.75 std

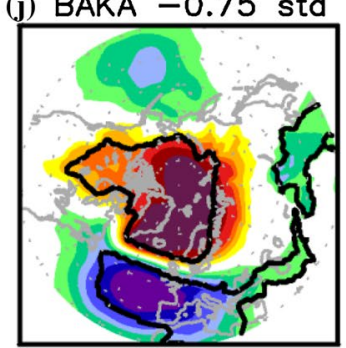

(k) GREEN -0.75 std

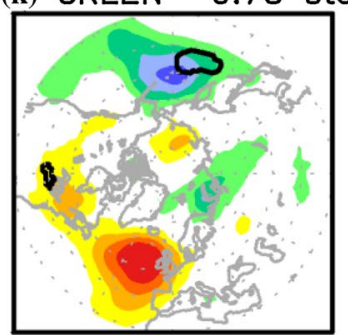

(g) BEAU 0.75 std

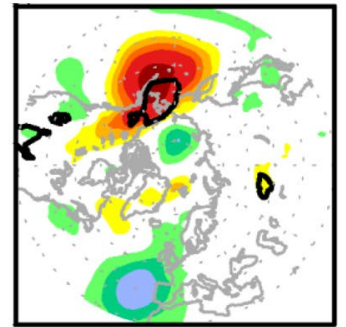

(c) GREEN 0.75 std

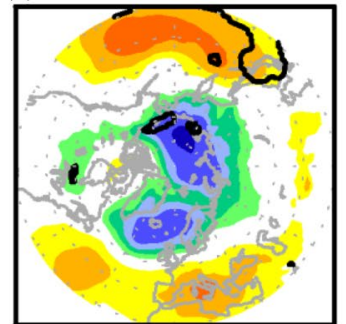

(d) LAB 0.75 std

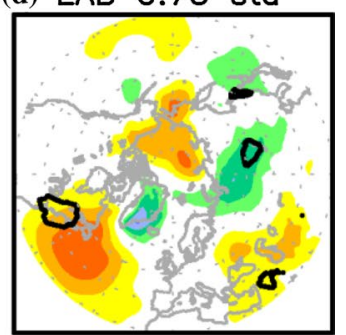

(h) CARC 0.75 std

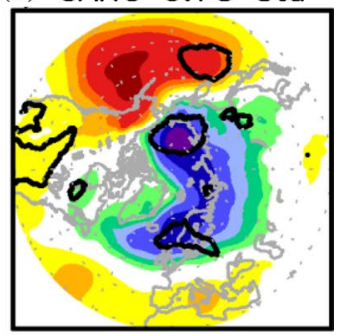

(I) LAB -0.75 std

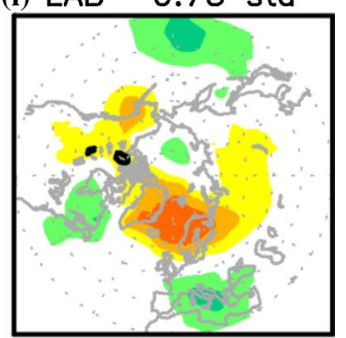

(p) CARC -0.75 std

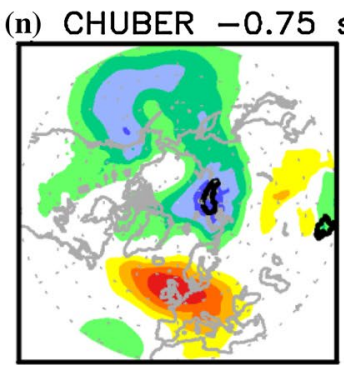

(o) BEAU -0.75 std
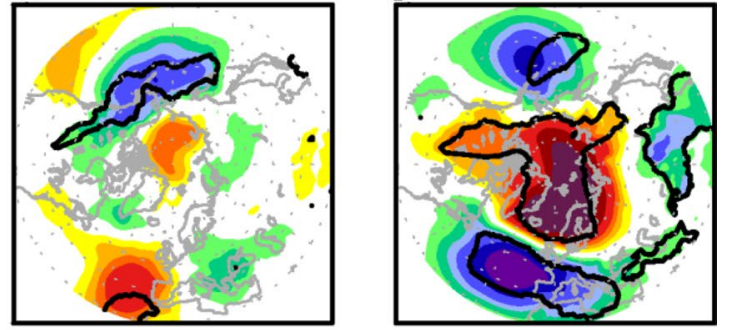

$\begin{array}{llllll}0.5 & 1 & 1.5 & 2 & 3 & 4\end{array}$

Fig. 9 SLP anomalies (in hPa) in the winter (DJF) after a November with high (a-h) and low (i-p) sea ice area exceeding \pm 0.75 standard deviation. All data are detrended. Black lines indicate significance at the $95 \%$ level

after high ice in many areas would lead to the conclusion that it might not matter too much where exactly the sea ice anomaly is situated in the high ice case or that the Arctic sea ice patterns are rather similar for high ice anomalies in most of the regions. This will be discussed more in Sect. 4. Interestingly, the response after high ice in LAPSIB is almost reversed over the North Atlantic-European Arctic area compared to the signal after high ice in most other areas. This is particularly striking since November ice area in LAPSIB is relatively well correlated to both $\mathrm{NH}$ and
CHUBER ice area. Furthermore, it would mean that the LAPSIB area is special compared to the other areas and it is not sufficient to have large positive ice anomalies somewhere in the Arctic for predicting winter atmospheric circulation anomalies in the North Atlantic-Arctic region.

Over the Pacific, the strongest response occurs after preceding high ice area in CHUBER and CARC. In contrast to the Atlantic-European Arctic area, the response to high LAPSIB ice anomalies has the same sign as after high ice in the other areas. 
The SLP anomaly patterns after low ice anomalies show a relatively high degree of symmetry to the high ice response for most sub-regions. However, the SLP response to low ice is less uniform and depends more on the region of the ice anomaly. After low ice in BAKA and CARC, we find a very strong negative NAO pattern, which is highly significant. This can be explained by the relatively high correlation between ice area in CARC and BAKA (Table 1) and particularly the low composites of BAKA and CARC consist of almost the same cases. The SLP signal to low $\mathrm{NH}$ ice is similar but less pronounced. The signal to low ice in CHUBER is not symmetric to the high ice case and shows almost no significance. After low LAPSIB ice, SLP is strongly reduced over the Nordic Seas and Arctic Ocean and significantly above normal from Newfoundland across the North Atlantic towards Central Europe and further to Siberia. Thus, the response to LAPSIB ice is again almost reversed to BAKA, NH and CARC, although the anomalies are slightly shifted towards the North Pole.

The anomaly patterns do not substantially change if we consider all cases exceeding ice anomalies of 0.5 or 1 standard deviation instead (not shown). This might indicate (a) $\mathrm{T} 2 \mathrm{M}, \mathrm{NH} 0.75$ std

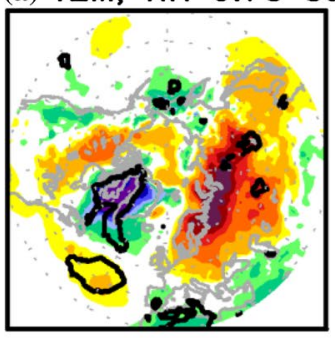

(e) LAPSIB 0.75 std

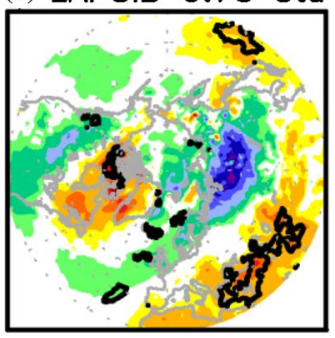

(i) $\mathrm{NH}-0.75 \mathrm{std}$

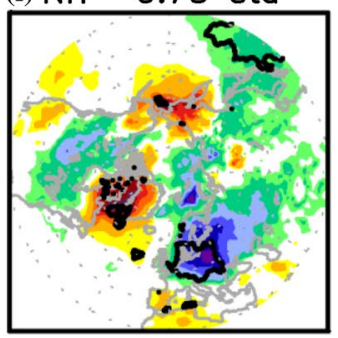

(m) LAPSIB -0.75 std
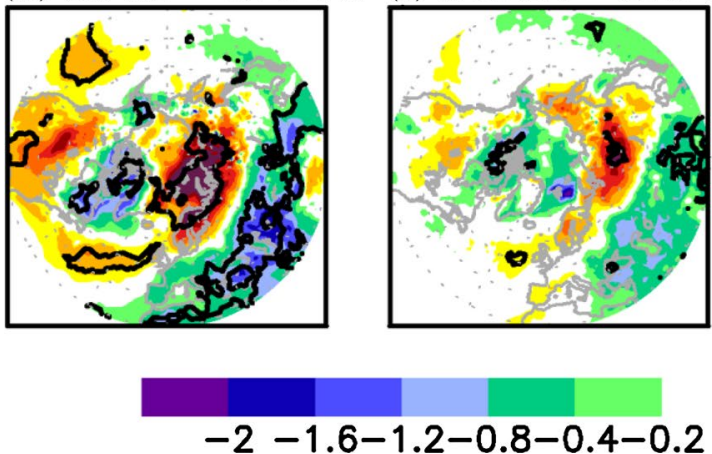

$$
-2-1.6-1.2-0.8-0.4-0.2
$$

(b) BAKA 0.75 std

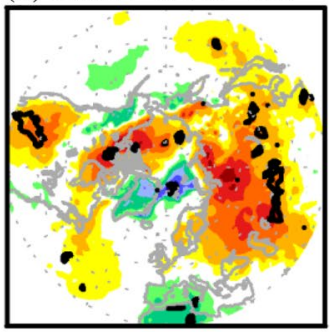

(f) CHUBER 0.75 std

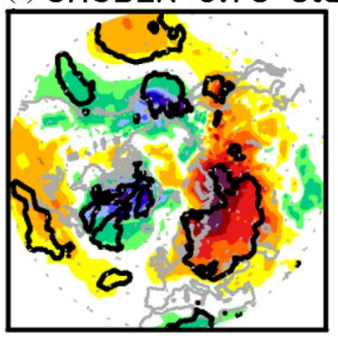

(j) BAKA -0.75 std

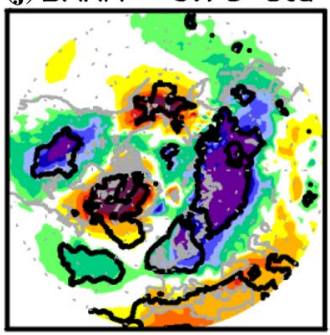

(n) CHUBER -0.75 std
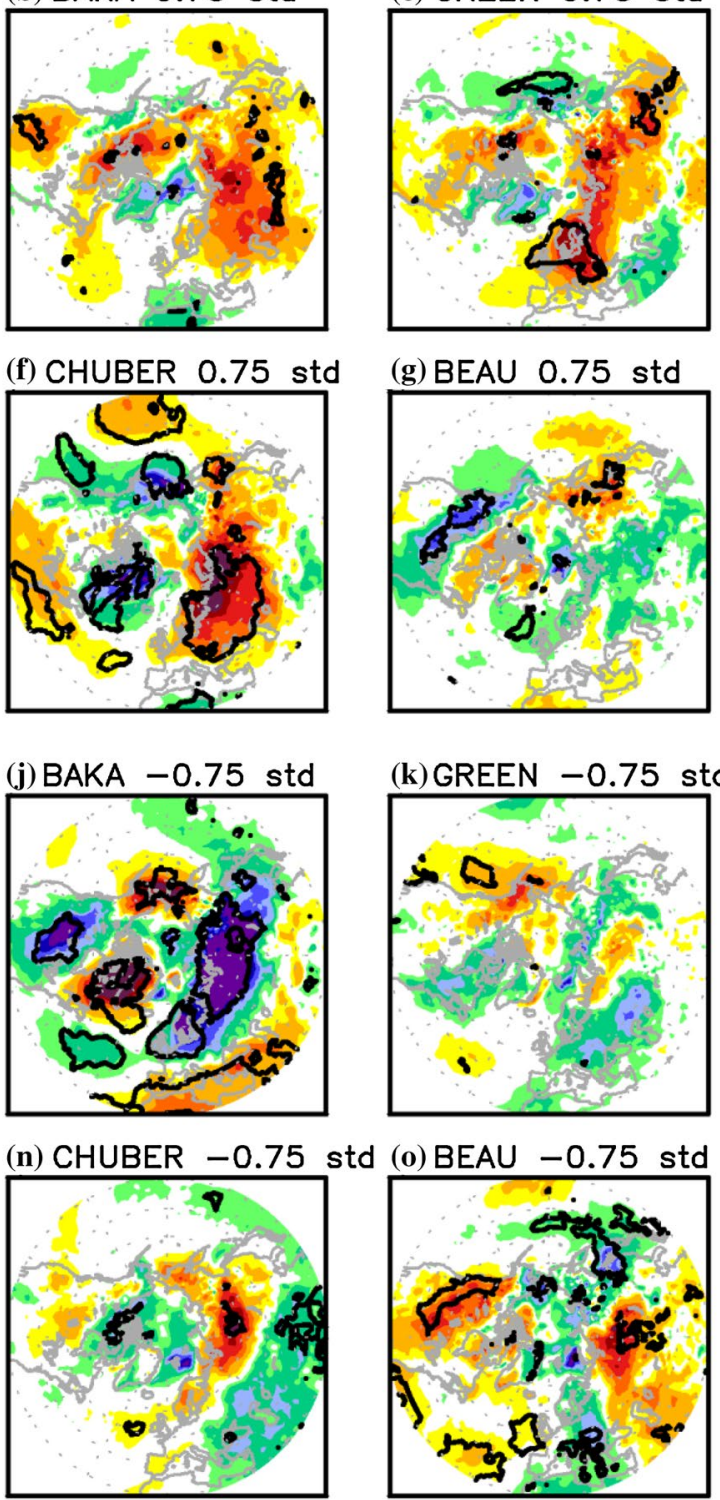

(g) BEAU 0.75 std
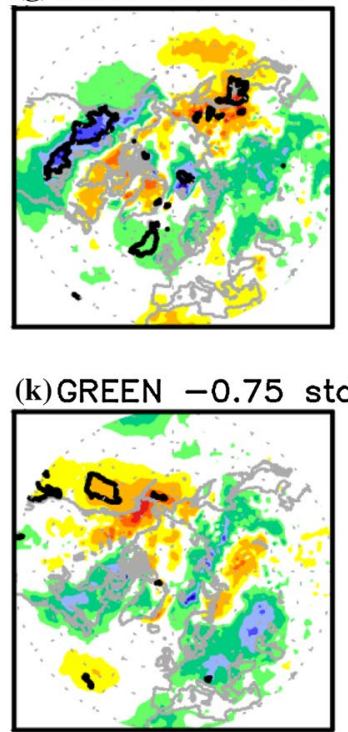

(d) LAB 0.75 std

(k) GREEN -0.75 std
(I) LAB -0.75 std

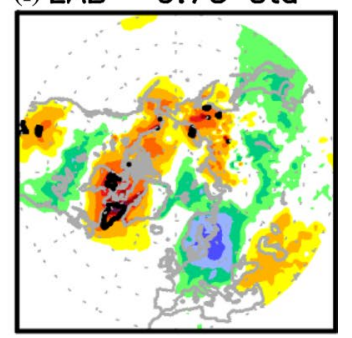

(p) CARC $-0.75 \mathrm{std}$

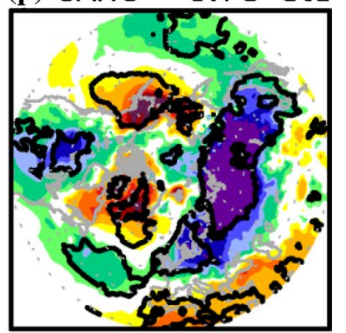

(h) CARC $0.75 \mathrm{std}$

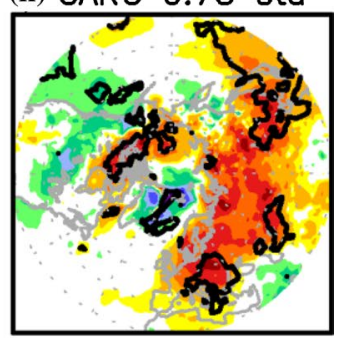

M.

$\begin{array}{llllll}0.2 & 0.4 & 0.8 & 1.2 & 1.6 & 2\end{array}$

Fig. 10 The same as Fig. 9 but for T2m anomalies (in Kelvin) 
that the asymmetric responses, which we find in a few of the areas are not only a feature of subsampling and that predictability of next winter atmospheric circulation might depend on the sign of the ice anomaly.

\subsubsection{Air temperature}

The response of winter T2m to severe ice conditions in the preceding November (Fig. 10) is strongly governed by the related SLP-response (compare Fig. 9). This leads to above normal temperatures in many European and Asian regions. However, amplitude and position of the anomalies differ. The most significant responses occur in eastern and northeastern Europe after high ice in CHUBER, in central and northern Europe after high ice in GREEN. In contrast, after high ice in LAPSIB, northern Europe and parts of Siberia are colder than normal while southeastern Europe experiences above normal temperatures.

Over North America, we find significantly negative anomalies in the northeast after high ice in $\mathrm{NH}$ and $\mathrm{LAB}$ and positive anomalies related to high ice in LABSIB, cold anomalies in central North America related to BEAU ice area, warm anomalies after high ice in BAKA in western United States and in Canada after high ice in GREEN.
For the low ice case, we find the largest and almost identically T2m signals after low ice in BAKA and CARC with significantly cold anomalies from mid-latitude North Atlantic over northern Europe across most of northern and midlatitudes of Asia. In eastern Siberia and Alaska, it is warmer than normal while further south over North America, a significantly cold anomaly occurs. Over the Greenland area and southern Europe/northern Africa region, significantly positive anomalies appear. The $\mathrm{T} 2 \mathrm{~m}$ response after low ice in LAPSIB is symmetric to the high ice case but amplitudes and significances are higher. Low ice in BEAU leads to a checkerboard pattern with positive anomalies over North America and central Siberia and cold anomalies over Europe and the northeastern Asia, Bering Sea area.

In the following, we analyze how often the simple forecast that temperature is warmer (colder) than normal in the winter following an autumn ice anomaly exceeding \pm 0.75 standard deviation would have been successful in the period 1980-2013 (Tables 3, 4 for September ice and November ice as predictor, respectively). We perform this forecast for nine different land areas in mid and high northern latitudes. If at least $75 \%$ of the cases show the same sign of the signal we marked the forecast bold in the table and call it in the following skillful. Note, that the $75 \%$-level is an
Table 3 Number of winters (DJF mean) in the land areas on the left side with positive $\mathrm{T} 2 \mathrm{~m}$ anomaly after positive (top row of each box) and negative (bottom row of each box) September ice anomalies exceeding \pm 0.75 standard deviation

\begin{tabular}{lllllllll}
\hline $\begin{array}{l}\text { Pos ice } \geq 0.75 \text { std } \\
\text { Neg ice } \leq 0.75 \text { std }\end{array}$ & NH & BAKA & GREEN & LAB & LAPSIB & CHUBER & BEAU & CARC \\
\hline Cent-West Europe & $3 / 7$ & $4 / 7$ & $\mathbf{8 / 1 0}$ & $2 / 5$ & $2 / 6$ & $\mathbf{7 / 8}$ & $4 / 7$ & $4 / 7$ \\
45-55N, 5W-20E & $4 / 11$ & $3 / 6$ & $\mathbf{1 / 6}$ & $2 / 3$ & $5 / 9$ & $5 / 7$ & $2 / 6$ & $3 / 5$ \\
North Europe & $3 / 7$ & $3 / 7$ & $5 / 10$ & $2 / 5$ & $2 / 6$ & $5 / 8$ & $3 / 7$ & $4 / 7$ \\
55-70N, 5E-35E & $5 / 11$ & $\mathbf{1 / 6}$ & $3 / 6$ & $\mathbf{0 / 3}$ & $5 / 9$ & $5 / 7$ & $4 / 6$ & $2 / 5$ \\
East Europe & $3 / 7$ & $5 / 7$ & $6 / 10$ & $2 / 5$ & $3 / 6$ & $5 / 8$ & $5 / 7$ & $3 / 7$ \\
40-60N, 15E-60E & $5 / 11$ & $2 / 6$ & $3 / 6$ & $2 / 3$ & $6 / 9$ & $\mathbf{6 / 7}$ & $3 / 6$ & $3 / 5$ \\
South Europe & $4 / 7$ & $3 / 7$ & $5 / 10$ & $2 / 5$ & $2 / 6$ & $5 / 8$ & $3 / 7$ & $5 / 7$ \\
30-45N, 5W-25E & $5 / 11$ & $3 / 6$ & $3 / 6$ & $2 / 3$ & $6 / 9$ & $4 / 7$ & $3 / 6$ & $3 / 5$ \\
West Asia & $5 / 7$ & $\mathbf{7 / 7}$ & $3 / 10$ & $3 / 5$ & $4 / 6$ & $4 / 8$ & $5 / 7$ & $4 / 7$ \\
40-60N, 60E-100E & $3 / 11$ & $\mathbf{1 / 6}$ & $2 / 6$ & $1 / 3$ & $4 / 9$ & $3 / 7$ & $3 / 6$ & $2 / 5$ \\
Middle Asia & $3 / 7$ & $4 / 7$ & $4 / 10$ & $2 / 5$ & $\mathbf{1 / 6}$ & $4 / 8$ & $3 / 7$ & $4 / 7$ \\
40-60N, 100-140E & $4 / 11$ & $\mathbf{1 / 6}$ & $3 / 6$ & $1 / 3$ & $4 / 9$ & $4 / 7$ & $\mathbf{1 / 6}$ & $2 / 5$ \\
East Siberia & $3 / 7$ & $3 / 7$ & $5 / 10$ & $3 / 5$ & $\mathbf{1 / 6}$ & $3 / 8$ & $3 / 7$ & $5 / 7$ \\
60-70N, 140E-180E & $7 / 11$ & $4 / 6$ & $4 / 6$ & $2 / 3$ & $4 / 9$ & $3 / 7$ & $3 / 6$ & $3 / 5$ \\
Alaska & $\mathbf{6 / 7}$ & $2 / 7$ & $5 / 10$ & $2 / 5$ & $3 / 6$ & $5 / 8$ & $\mathbf{6 / 7}$ & $2 / 7$ \\
60-70N, 130-170W & $5 / 11$ & $3 / 6$ & $3 / 6$ & $2 / 3$ & $3 / 9$ & $5 / 7$ & $3 / 6$ & $3 / 5$ \\
North Canada & $\mathbf{6 / 7}$ & $3 / 7$ & $4 / 10$ & $2 / 5$ & $3 / 6$ & $5 / 8$ & $5 / 7$ & $3 / 7$ \\
58-68N, 90-130W & $3 / 11$ & $2 / 6$ & $2 / 6$ & $1 / 3$ & $\mathbf{1 / 9}$ & $\mathbf{1 / 7}$ & $4 / 6$ & $\mathbf{1 / 5}$ \\
NE United States & $4 / 7$ & $5 / 7$ & $5 / 10$ & $\mathbf{1 / 5}$ & $\mathbf{5 / 6}$ & $4 / 8$ & $5 / 7$ & $3 / 7$ \\
35-45N, 70-90W & $6 / 11$ & $2 / 6$ & $3 / 6$ & $1 / 3$ & $6 / 9$ & $4 / 7$ & $4 / 6$ & $\mathbf{4 / 5}$ \\
\hline
\end{tabular}

The number behind the denominator indicates the total number of events exceeding $+0.75(-0.75)$ standard deviation. "N1/N2" means e.g. that N2 cases with September ice anomalies exceeding $+0.75(-0.75)$ standard deviation exist and $\mathrm{N} 1$ out of $\mathrm{N} 2$ cases are followed by a positive (negative) temperature anomaly in the following winter. If $75 \%$ or more of the cases $(\mathrm{N} 1 / \mathrm{N} 2 \geq 0.75)$ are warmer or colder than normal, the numbers are marked bold 
Table 4 Same as Table 3 but for November ice anomalies

\begin{tabular}{lllllllll}
\hline Pos ice $>0.75$ std & NH & BAKA & GREEN & LAB & LAPSIB & CHUBER & BEAU & CARC \\
Neg ice $<-0.75$ std & & & & & & & & \\
\hline Cent-West Europe & $4 / 7$ & $3 / 8$ & $\mathbf{6 / 8}$ & $4 / 8$ & $4 / 7$ & $\mathbf{6 / 7}$ & $3 / 6$ & $4 / 6$ \\
45-55N, 5W-20E & $3 / 9$ & $2 / 7$ & $3 / 8$ & $3 / 10$ & $2 / 6$ & $5 / 8$ & $3 / 5$ & $2 / 6$ \\
North Europe & $\mathbf{6 / 7}$ & $5 / 8$ & $\mathbf{6 / 8}$ & $5 / 8$ & $3 / 7$ & $\mathbf{1 / 7}$ & $3 / 6$ & $\mathbf{5 / 6}$ \\
55-70N, 5E-35E & $\mathbf{2 / 9}$ & $\mathbf{1 / 7}$ & $3 / 8$ & $4 / 10$ & $4 / 6$ & $3 / 8$ & $2 / 5$ & $\mathbf{1 / 6}$ \\
East Europe & $5 / 7$ & $\mathbf{6 / 8}$ & $\mathbf{6 / 8}$ & $4 / 8$ & $4 / 7$ & $\mathbf{6 / 7}$ & $3 / 6$ & $4 / 6$ \\
40-60N, 15E-60E & $\mathbf{2 / 9}$ & $2 / 7$ & $3 / 8$ & $5 / 10$ & $3 / 6$ & $4 / 8$ & $3 / 5$ & $2 / 6$ \\
South Europe & $\mathbf{1 / 7}$ & $\mathbf{2 / 8}$ & $5 / 8$ & $3 / 8$ & $4 / 7$ & $2 / 7$ & $3 / 6$ & $4 / 6$ \\
30-45N, 5W-25E & $6 / 9$ & $\mathbf{6 / 7}$ & $3 / 8$ & $5 / 10$ & $2 / 6$ & $5 / 8$ & $2 / 5$ & $4 / 6$ \\
West Asia & $\mathbf{6 / 7}$ & $\mathbf{6 / 8}$ & $4 / 8$ & $4 / 8$ & $3 / 7$ & $5 / 7$ & $\mathbf{1 / 6}$ & $4 / 6$ \\
40-60N, 60E-100E & $4 / 9$ & $3 / 7$ & $4 / 8$ & $5 / 10$ & $\mathbf{1 / 6}$ & $3 / 8$ & $3 / 5$ & $2 / 6$ \\
Middle Asia & $5 / 7$ & $5 / 8$ & $5 / 8$ & $4 / 8$ & $4 / 7$ & $4 / 7$ & $4 / 6$ & $\mathbf{5 / 6}$ \\
40-60N, 100-140E & $\mathbf{2 / 9}$ & $\mathbf{1 / 7}$ & $\mathbf{2 / 8}$ & $3 / 10$ & $2 / 6$ & $4 / 8$ & $\mathbf{1 / 5}$ & $\mathbf{0 / 6}$ \\
East Siberia & $\mathbf{1 / 7}$ & $4 / 8$ & $\mathbf{2 / 8}$ & $4 / 8$ & $3 / 7$ & $\mathbf{0 / 7}$ & $4 / 6$ & $2 / 6$ \\
60-70N, 140E-180E & $\mathbf{7 / 9}$ & $\mathbf{6 / 7}$ & $4 / 8$ & $6 / 10$ & $4 / 6$ & $5 / 8$ & $2 / 5$ & $\mathbf{1 / 6}$ \\
Alaska & $4 / 7$ & $4 / 8$ & $\mathbf{6 / 8}$ & $4 / 8$ & $4 / 7$ & $3 / 7$ & $2 / 6$ & $4 / 6$ \\
60-70N, 130-170W & $5 / 9$ & $\mathbf{6 / 7}$ & $5 / 8$ & $7 / 10$ & $\mathbf{1 / 6}$ & $3 / 8$ & $2 / 5$ & $\mathbf{6 / 6}$ \\
North Canada & $5 / 7$ & $\mathbf{6 / 8}$ & $\mathbf{6 / 8}$ & $\mathbf{2 / 8}$ & $4 / 7$ & $4 / 7$ & $4 / 6$ & $\mathbf{5 / 6}$ \\
58-68N, 90-130W & $3 / 9$ & $2 / 7$ & $4 / 8$ & $3 / 10$ & $2 / 6$ & $\mathbf{2 / 8}$ & $3 / 5$ & $2 / 6$ \\
NE United States & $4 / 7$ & $4 / 8$ & $\mathbf{6 / 8}$ & $5 / 8$ & $2 / 7$ & $5 / 7$ & $2 / 6$ & $3 / 6$ \\
35-45N, 70-90W & $4 / 9$ & $3 / 7$ & $4 / 8$ & $5 / 10$ & $\mathbf{5 / 6}$ & $5 / 8$ & $3 / 5$ & $3 / 6$ \\
\hline
\end{tabular}

arbitrary limit, which is neither considering the number of Septembers/Novembers exceeding \pm 0.75 standard deviation, nor the different $\mathrm{T} 2 \mathrm{~m}$ variance of the land regions to predict.

Using September sea ice areas as predictor, we find two combinations, providing a good forecast skill both after low and high ice anomalies: the central-western Europe $\mathrm{T} 2 \mathrm{~m}$ after ice anomalies in the Greenland Sea (warm after high ice, cold after low ice) and western Asia T2m after BAKA ice anomalies (warm after high ice, cold after low ice). However, there are a number of land areas showing good forecasts skill after either high or low ice anomalies (e.g. warm winter in ALASKA after high ice in $\mathrm{NH}$ or cold winter in NCAN after low ice in LAPSIB).

Using November sea ice area anomalies in our eight Arctic regions as predictor instead, we find twice as many skillful predictor-predictand pairs (43 compared to 21 if using September ice). For each land region, at least one predictor region with high ice and one with low ice exist, which provides a skillful prediction. This means that in at least $50 \%$ of all winters, a skillful forecast is possible for each of the Arctic and mid-latitude land areas. Sea ice anomalies in BAKA, NH and GREEN are the predictors leading to the largest number of skillful predictions. However, land regions exist where ice variations in other Arctic regions provide a better forecast, which indicates the importance to take all Arctic regions into account. Simple statistical forecasts like this provide a good benchmark for dynamical seasonal predictions with models.

\section{Processes}

The underlying mechanisms of the sea ice effect on the large scale atmospheric circulation are still debated. The most common explanation in later studies is a link via the stratosphere (e.g. Cohen et al. 2012; Jaiser et al. 2013; Garcia-Serrano and Frankkignoul 2014). They argue that reduced autumn sea ice and thus more humid air affects precipitation patterns which lead to enhanced autumn snow cover over Siberia. Cohen et al. (2007) showed that this can affect the Siberian High and changes planetary wave fluxes into the stratosphere. Also a more direct link between sea ice and stratospheric circulation through generating anomalous Rossby waves (Honda et al. 2009; Peings and Magnusdottir 2014) or by preconditioning static stability and baroclinicity (Rinke et al. 2013) has been suggested. All these suggested processes might slow down the Polar Vortex, which in turn feeds back to the troposphere leading to a negative NAO/AO signal.

Earlier studies (Magnusdottir et al. 2004; Deser et al. 2004; Alexander et al. 2004) suggested a link via the meridional temperature gradient caused by sea ice anomalies leading to a baroclinic adjustment to the introduced mass gradient anomaly. In this section, we will shortly discuss 
these different hypotheses. However, it would go beyond the scope of this study to analyze the underlying processes in detail.

\subsection{Stratosphere}

A number of studies (Christiansen 2001; Baldwin et al. 2003; Charlton et al. 2004) indicate an impact of the stratospheric circulation on the troposphere at lead times of a few weeks. Figure 11 shows that the early winter (November, December, January average, NDJ) Polar Vortex, which we defined here as zonal mean at $65^{\circ} \mathrm{N}$ of the zonal wind in $10 \mathrm{hPa}$ height, is significantly correlated with the winter (DJF) SLP in the detrended ERA-interim data. The SLP response reminds a positive NAO pattern for strong Polar Vortexes. However, the positive pole is shifted somewhat to the east compared to the NAO-pattern. The correlation of the Polar Vortex to T2m reveals significantly positive values from northern and eastern Europe across mid and high latitudes of Asia to the Pacific Ocean and highly negative correlations from northeastern Africa across southern Asia to the Pacific and also in the Labrador and Irminger Seas. These SLP and T2m patterns can be found in the winter SLP (Figs. 4, 9) and T2m responses (Figs. 7, 10) to November and partly to September sea ice anomalies (Figs. 3, 6).

September and November sea ice anomalies affect the winter geopotential height pattern throughout the entire troposphere (not shown). The response patterns and correlation coefficients are not strongly varying with height in the troposphere. However, in September, ice area in none of the Arctic sub-regions is significantly correlated to the NDJ Polar Vortex (max correlation coefficient reaches $r=0.27$ ). The same is true for correlations between September sea ice and the $10 \mathrm{hPa}$ geopotential height field. Also ice variations in BAKA and BEAU, where SLP showed a stronger response to, do not show any significant correlations to the stratosphere. If we only consider large ice anomalies, the signal in the stratosphere is getting somewhat larger (not shown). However, similar stratospheric signals are followed by strongly different surface signals and vice versa. Thus, interactions with the stratosphere can-if at all—only be a contributing factor for explaining the atmospheric signals after ice anomalies in September.

This changes somewhat when we use November sea ice variations: now correlations between ice area in several Arctic sub regions and the NDJ Polar Vortex reach up to 0.5. These regions are NH, CARC, BAKA and BEAU. While NH, CARC and BAKA show a similar tropospheric response, the response to BEAU ice anomalies is quite different. We do not find any significant correlation between LAPSIB and the Polar Vortex. Although an involvement of the stratosphere seems more likely when considering November ice anomalies, interactions with the stratosphere are probably not the major cause for the near surface response in the following winter in our study.

\subsection{Meridional temperature gradient}

The meridional temperature gradient in high northern latitudes is mainly affected by the position of sea ice anomalies. According to studies by Alexander et al. (2004) and Deser et al. (2004), an increased meridional temperature gradient would lead to increased cyclonic activity in order to re-establish the original mass and heat-balances. A recent study by Inoue et al. (2012) suggested that the meridional temperature gradient due to ice variations in the Barents Sea is the main reason for the observed SLP anomalies and the connected "warm Arctic-cold continent" temperature patterns in recent years.
Fig. 11 Correlation between Polar Vortex in $10 \mathrm{hPa}$ height and $65^{\circ} \mathrm{N}$ in early winter (average over NDJ) and winter SLP (left, average over DJF) and winter mean $\mathrm{T} 2 \mathrm{~m}$ (right)

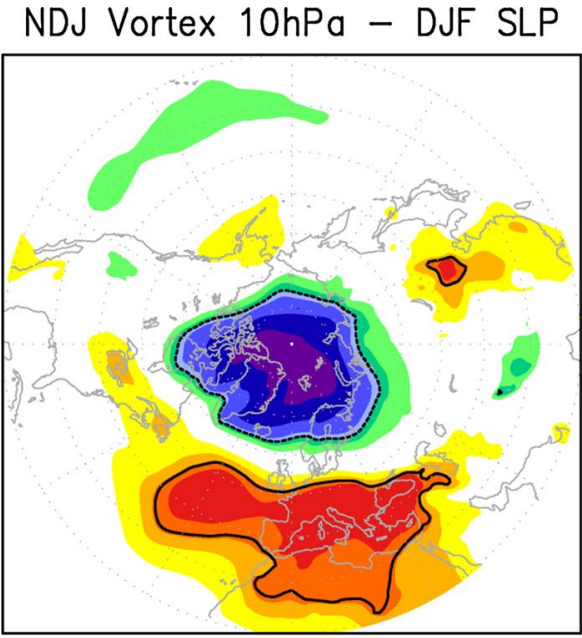
NDJ Vortex $10 \mathrm{hPa}-$ DJF T2m

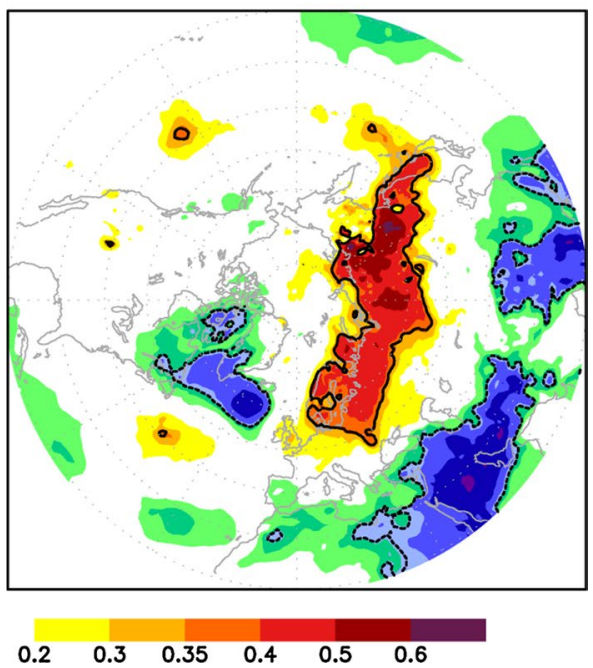


A number of studies showed predictability of sea ice anomalies up to 6 months and more (Guemas et al. 2014; Tietsche et al. 2014; Chevallier and Salas-Mélia 2012; Blanchard-Wrigglesworth et al. 2011a, b; Koenigk and Mikolajewicz 2009; Koenigk et al. 2009) mainly due to persistence, reemergence and advection processes. Thus, September and even more November sea ice anomalies (Chevallier et al. 2013) could lead winter ice anomalies, which in turn affect the meridional temperature gradient and thus atmospheric circulation.

(a) SIC, NH 0.75 std

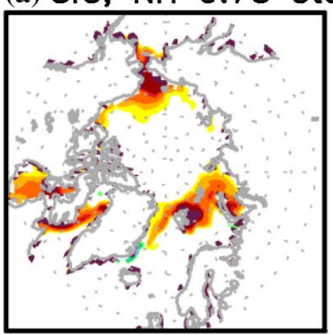

(e) LAPSIB 0.75 std

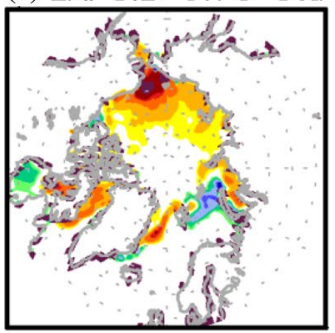

(i) $\mathrm{NH}-0.75$ std

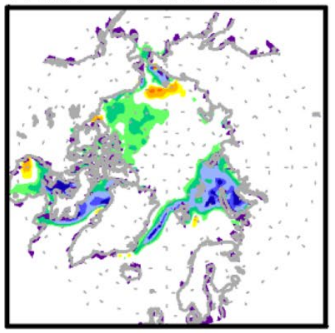

(m) LAPSIB -0.75 std
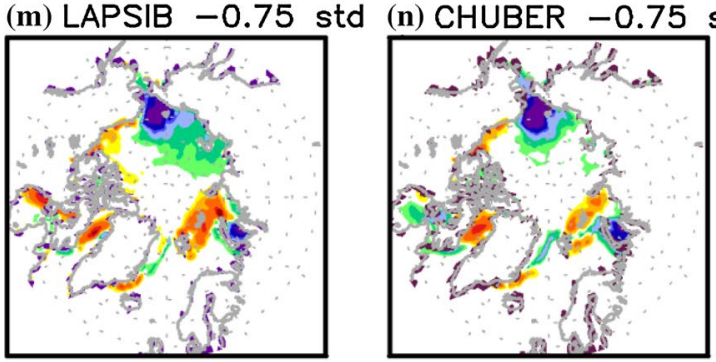

(j) BAKA -0.75 std
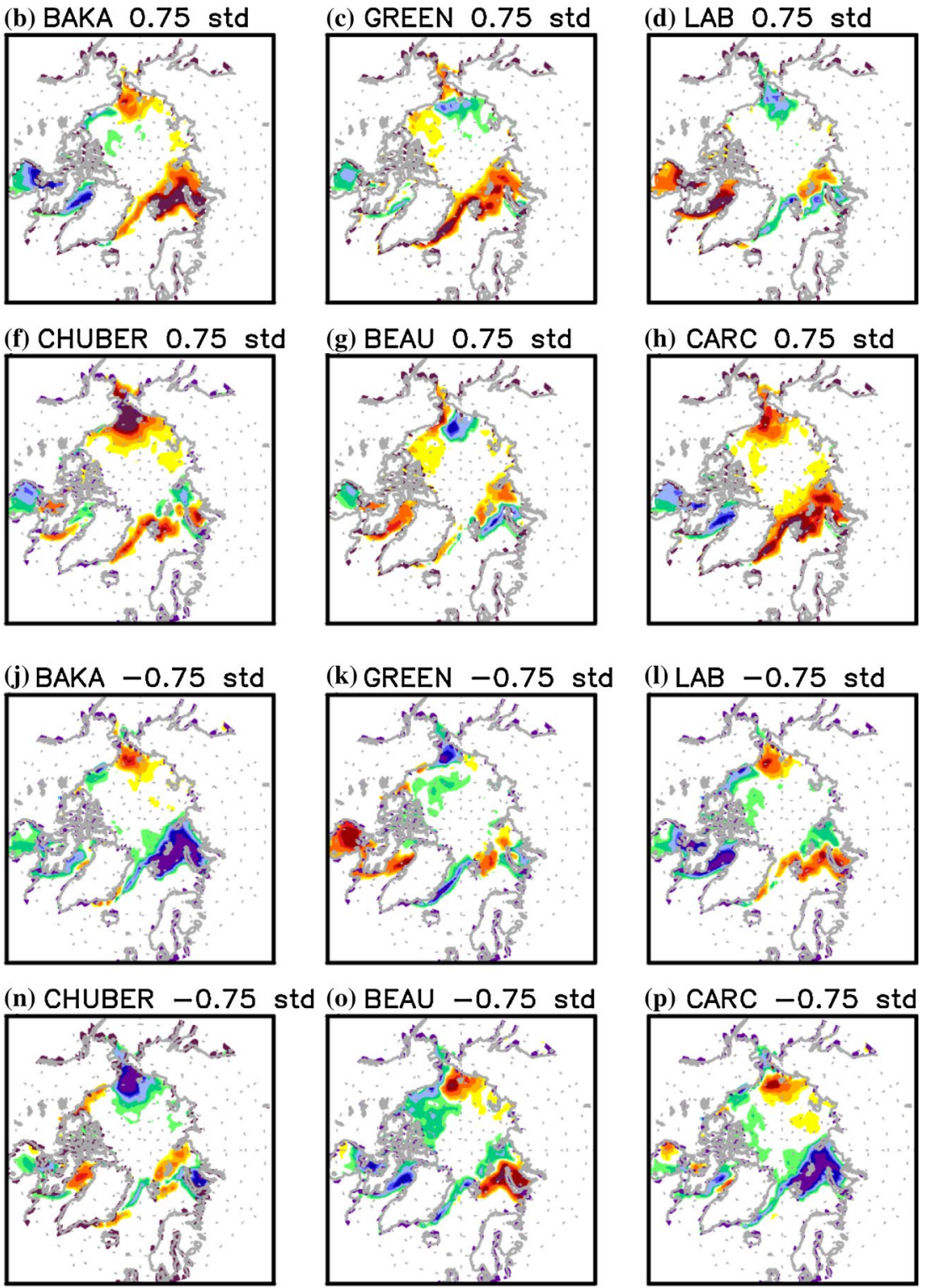

(d) LAB 0.75 std
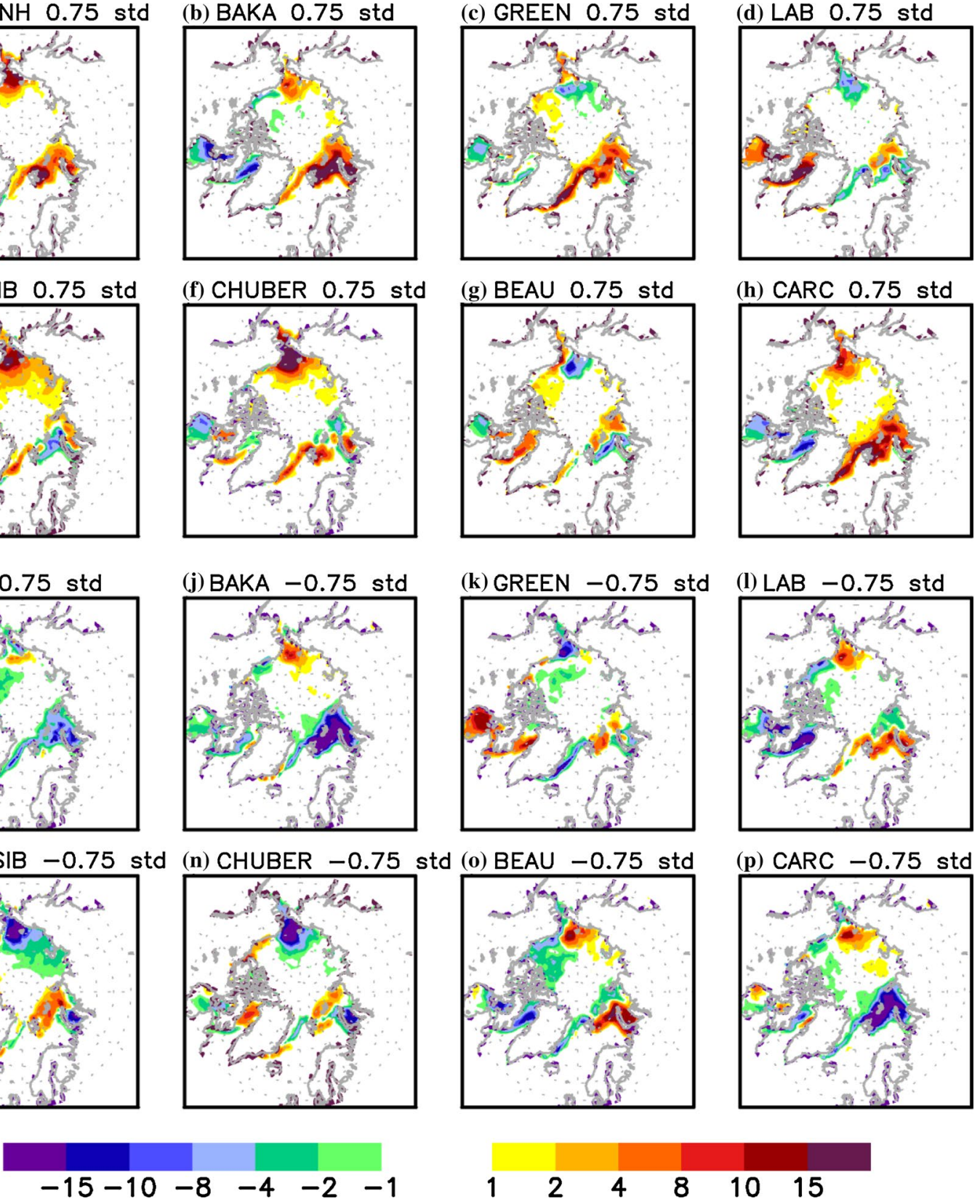

Fig. 12 Sea ice concentration anomalies (in \%) in November during a November with high (a-h) and low (i-p) sea ice area exceeding \pm 0.75 standard deviation. All data are detrended 
similar anomalies in the meridional temperature gradient. Comparing Figs. 9 and 12, shows that all regions with positive ice anomalies in the Greenland and Barents Seas in November are connected to a winter SLP pattern similar to the positive NAO case. Those regions that at the same time show a positive anomaly in the Labrador Sea lead to an even more pronounced positive pole of the NAO, which is also more extended towards northeastern Canada. This is the case after high ice in LAB, $\mathrm{NH}, \mathrm{CHUBER}$ while particularly high ice in CARC and GREEN leads to less pronounced SLP anomalies in the subtropical North Atlantic (compare Fig. 9). High ice areas in almost all regions are related to a positive winter SLP anomaly over the North Pacific; sign and amplitude of the November ice anomaly in the Chukchi Sea/ Bering Strait area seems to be of minor importance. High ice area in LAPSIB - followed by a negative NAO-like SLP pattern-is connected to a negative ice anomaly in the Barents Sea but to positive anomalies in the Greenland and Labrador Seas and positive ice anomalies occur in the entire $90^{\circ} \mathrm{E}-270^{\circ} \mathrm{E}$ section of the Arctic. Interestingly, the SLP pattern is not completely reversed after high ice in LAPSIB but SLP over the North Pacific is also positive as after high ice in most other regions.

A positive November ice anomaly in the Barents Sea area and thus enhanced meridional temperature gradients pointing into this area might lead to enhanced baroclinicity and thus more cyclonic activity and the formation of a positive NAO/AO like SLP pattern. Anomalies in the Greenland and Labrador Sea seem to modulate the strength of this response.

The light ice case shows for many regions a symmetric ice distribution compared to the high ice case. Interestingly, the ice anomalies in BAKA and CARC are almost exactly the same and in contrast to the high ice case, low ice in BAKA is connected to anomalies of the same sign both east and west of Greenland meaning a reduction in the meridional temperature gradient on both sides of Greenland. This seems to result in a stronger SLP response in the light ice case strengthening the hypothesis of the modulating character of sea ice in the Labrador Sea region.

Based on these results, which agree well with results from AGCM experiments by Alexander et al. (2004) and Deser et al. (2004), we speculate that the meridional temperature gradient due to Arctic ice anomalies might play an important role for the SLP response to ice anomalies. However, it can not explain the entire response either.

Furthermore, it is possible that sea ice anomalies coexist with other large scale features as e.g. SST anomalies, land surface-snow and moisture anomalies, which might play a role for the large scale atmospheric response as well.

\section{Discussion}

\subsection{Persistence}

Comparing the predictive skill of a prediction to the skill arising from the persistence of a signal is a simple measure to judge the usefulness of a prediction. As persistence, we define here the correlation between autumn (September or November) SLP and T2m and the following winter SLP and T2m (Fig. 13). The persistence of both September and November SLP anomalies is small in almost all northern mid and high latitude areas. Only over the subtropical Pacific larger areas with stronger persistence occur. The predictive skill using sea ice area variations as predictor exceeds the persistence in most areas. For T2m, we find a larger persistence as for SLP, particularly over the ocean. For temperature over these ocean areas, the persistence outperform the sea ice area variations as predictor. However, over the continents, persistence is small and sea ice area variations provide improved skill.

\subsection{Robustness}

One caveat of this study is the short period of observations and reanalysis data. This raises questions about the robustness of the signal found in this study. In the following, we compare the results based on ERA-interim reanalysis data and OSISAF satellite sea ice data to results from NCEP/ NCAR reanalysis data (Kalnay et al. 1996). Both for temperature and SLP, the results agree relatively well for the period 1980-2013. As an example, Fig. 14 shows the results for ice variations in the BAKA area: while the correlation with SLP is very similar in ERA-interim (Fig. 4) and NCEP/NCAR reanalysis, some differences occur between the correlations with T2m (compare Fig. 7). This suggests that our main results are robust across data sets. However, Fig. 14c, d show a substantially reduced link between November sea ice area in the BAKA area and winter SLP and T2m if using NCEP/NCAR-reanalysis data between 1960 and 2013. Between, 1960 and 1980, ice area variations in the BAKA region even lead to the opposite SLP pattern compared to 1980-2013, although much less pronounced and not significant. It remains unclear if this means that the link between ice and winter climate is not robust over time or if sea ice concentrations are too uncertain in this pre-satellite period. Note, that while we have a certain confidence to the sea ice extent in the sea ice data before 1980, sea ice concentration data needed to calculate our ice area indices are not reliable in the pre-satellite period.

The time series used in this study are not only relatively short but also originate from a period in transition. Given the 
Fig. 13 Correlation between September SLP and following winter mean (DJF) SLP (a), September T2m and DJF T2m (b), November SLP and DJF SLP (c) and November T2m and DJF T2m (d) (a)

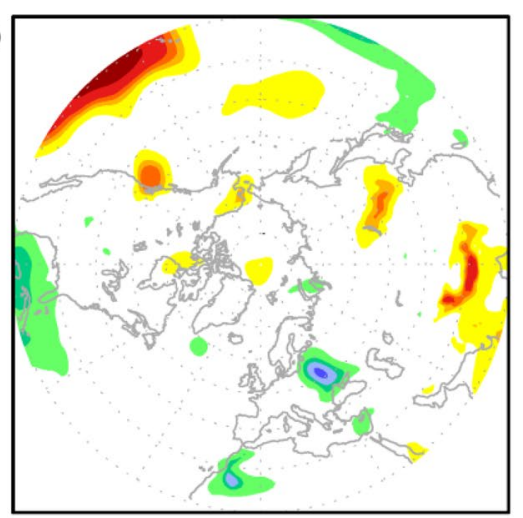

(c)

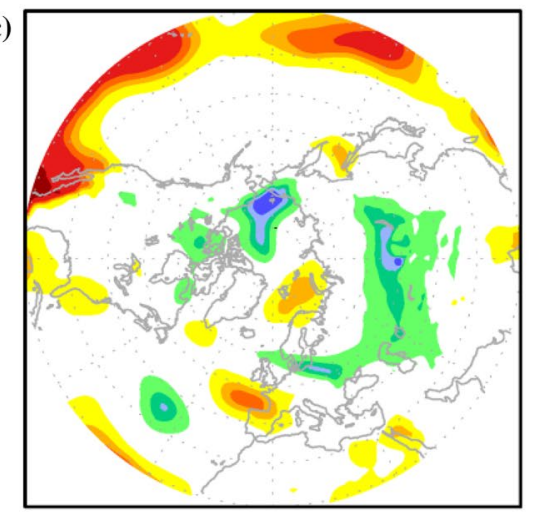

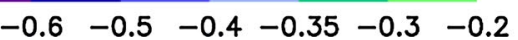

(b)

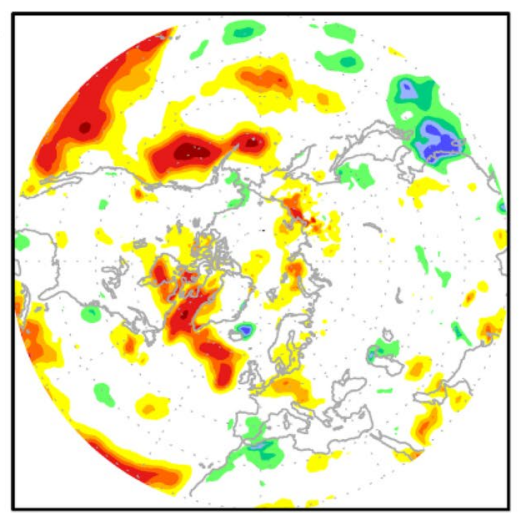

(d)

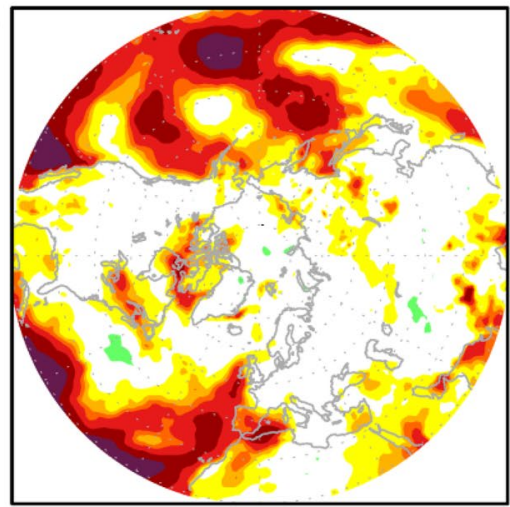

$\begin{array}{llllll}0.2 & 0.3 & 0.35 & 0.4 & 0.5 & 0.6\end{array}$ strong sea ice reductions in this period, high ice anomalies in recent years from the detrended time series would have been low ice anomalies in the first two decades of the time period using raw data. On the other hand, in a warming climate, thus with a locally warmer atmosphere, warmer southerly latitudes and generally reduced sea ice concentration and extent, the same ice anomaly in the 2000s would possibly have a different effect as in the 1980s. Composites from the raw ERAinterim reanalysis data (not shown) provide relatively similar results as from the detrended data. However, the response is generally larger, particularly over the Arctic Ocean area. The response in the raw data combines the signal from the trend and the signal of the ice. Since temperature and sea ice trend are obviously linked, it is not surprising that the signal is stronger in the raw data. To determine predictability of natural climate variations using sea ice as predictor, which is the main aim of this study, is difficult from the raw data.

\section{Summary and conclusions}

The impact of autumn sea ice variations in eight different Arctic regions on the winter climate conditions in mid and high northern latitudes has been analyzed using ERA-interim reanalysis and satellite data. We used detrended data and performed both correlation and composites analyses to assess the seasonal predictability connected to the different ice areas. We find significant correlations between ice areas in both September and November and winter SLP, T2m and P. However, results differ substantially dependent on the use of September or November ice and maximum correlations do not exceed 0.6 except for very small regions. In general, we find a slight improvement in the predictability when starting from November sea ice conditions compared to September ice conditions. This is particularly the case when using the entire Arctic sea ice area, Barents/Kara Sea ice, Central Arctic ice and ice area in the Laptev/East Siberian Seas as predictor: starting from November, we find a winter SLP response, which resembles the NAO or AO pattern for the first three areas (negative NAO/AO after low ice); high ice in Laptev/East Siberian Seas is followed by reduced SLP over large parts of Europe, northern Canada and eastern Asia. Related to this, the impact of November sea ice on blocking over the Euro-Atlantic region is substantially increased compared to September ice. Particularly ice variations along the Siberian coast are of importance for the blocking. The winter SLP response to September ice area variations does not 
Fig. 14 Correlation between November ice area in Barents and Kara Sea area and following winter (DJF) SLP (a, c) and $\mathrm{T} 2 \mathrm{~m}(\mathbf{b}, \mathbf{d})$ for 1980-2013 (a, b) and 1960-2013 (c, d) in the NCEP/NCAR reanalysis data (a)

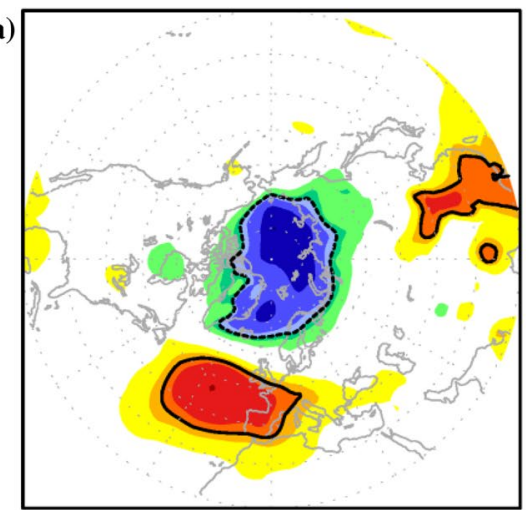

(c)

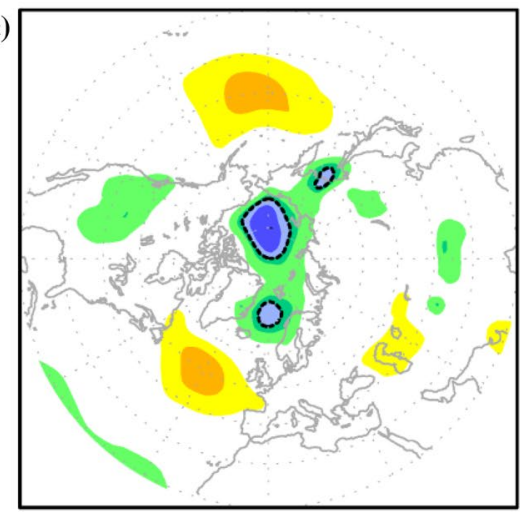

$\begin{array}{llllll}-0.6 & -0.5 & -0.4 & -0.35 & -0.3 & -0.2\end{array}$ (b)

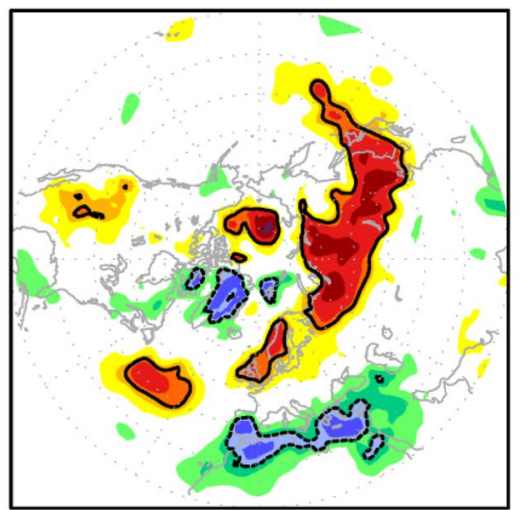

(d)

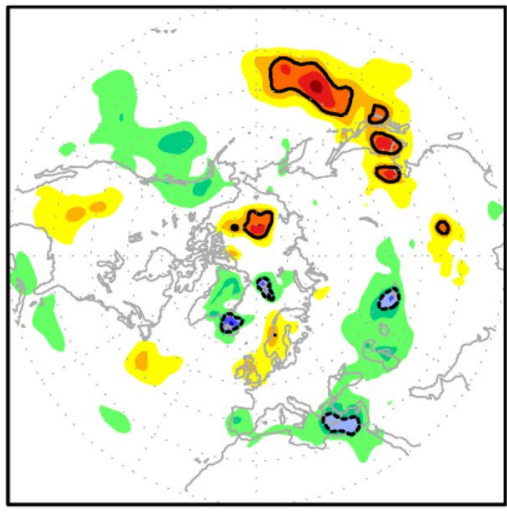

0.2

$\begin{array}{lllll}0.3 & 0.35 & 0.4 & 0.5 & 0.6\end{array}$ show strong similarity to the NAO-pattern, which is different to preceding studies. One reason for this might be differences in detrending techniques. We found that using linear detrending instead of detrending the periods 19801999 and 2000-2013 separately, leads to a more NAO-like response, although somewhat shifted to the east. However, the correlations with September ice in the Barents/Kara Sea area are highly significant from the Nordic Seas across Scandinavia to Eastern Asia. The response to ice variations in the Beaufort Sea are large over the eastern mid and subtropical North Pacific and parts of the North Atlantic and Europe and also the response to Greenland Sea ice area variability shows a number of significant areas. In September, the Greenland Sea ice is the best predictor for central and western European winter T2m; Barents/Kara Sea area is best for mid-latitudes of Eastern Europe, Asia and the western Pacific. North American T2m is best predictable using ice areas from Laptev Sea to Beaufort Sea as predictor.

The composites indicate that the response of climate to ice variations is not entirely linear. Thus, the predictability might depend on the sign and the amplitude of the preceding ice anomaly. This result agrees with findings from Petoukhov and Semenov (2010) showing that the atmospheric response to sea ice anomalies in the Barents
Sea largely depends on the amplitude of the ice anomaly. Interestingly, we find that the response to November sea ice variations (Figs. 10,11) is much more symmetric than the response to September ice anomalies (not shown). This might explain the smaller correlations with September ice but might also indicate that the response to September ice variations is less robust than to November ice variations.

November sea ice area in the Greenland and Barents Seas seems to play a dominant role in determining the sign of the NAO in the following winter, while sea ice anomalies in Labrador Sea are modulating extension and amplitude of the NAO-pattern. The process connecting the ice anomalies with the large scale atmospheric response can not clearly be determined. Many previous studies suggested a link via the stratosphere; however we find only for November significant correlations up to 0.5 between sea ice area and the polar vortex. We thus hypothesize that the response is very likely a combination of different factors including increased baroclinicity due to changing meridional temperature gradients and troposphere-stratosphere interaction to mid-latitude circulation anomalies. Furthermore, most ice anomalies are mainly caused by atmospheric circulation anomalies, which also introduce e.g. SST anomalies, land surface-snow and moisture anomalies co-existing with the 
ice anomalies. At the same time long-term oceanic variations, which might be related to low-frequency ice variations, could lead to additional surface anomalies. It is thus unclear if the responses shown in lag-correlations and composites are really only caused by the ice anomalies.

Another caveat of this study is that time series are short and originate from a period of changing climate conditions. The link between sea ice area variations and winter atmospheric conditions is weak before 1980. However, it remains unclear if this is due to an unstable temporal relation or unreliable sea ice concentration data before 1980 . To overcome these caveats, the use of long climate model simulations and model sensitivity experiments is needed. Such studies have already been performed with single models. However, since all modeling studies suffer from both model insufficiencies and unavoidable inconsistencies in the experiment setups, coordinated multi model, multiexperiment-efforts are necessary.

Despite, the caveats mentioned above, this study shows once again that sea ice plays an important role for seasonal predictions. It is thus highly important that sea ice is well initialized and well simulated in the seasonal prediction tools to improve predictions for mid and high-latitudes.

Acknowledgments This study has been made possible by support of the Rossby Centre at the Swedish Meteorological and Hydrological Institute (SMHI) together with the NORDFORSK Top Level Research Initiative, Project No. 61841-GREENICE and the EU-FP7 Project SPECS.

Open Access This article is distributed under the terms of the Creative Commons Attribution 4.0 International License (http://creativecommons.org/licenses/by/4.0/), which permits unrestricted use, distribution, and reproduction in any medium, provided you give appropriate credit to the original author(s) and the source, provide a link to the Creative Commons license, and indicate if changes were made.

\section{References}

Alexander M, Bhatt U, Walsh J, Timlin M, Miller J, Scott J (2004) The atmospheric response to realistic Arctic sea ice anomalies in an AGCM during winter. J Clim 17:890-905

Årthun M, Schrum C (2010) Ocean surface heat flux variability in the Barents Sea. J Mar Syst 83:88-98

Baldwin M, Stephenson D, Thompson D, Dunkerton T, Charlton A, O'Neill A (2003) Stratospheric memory and skill of extendedrange weather forecasts. Science 301:636-640

Barriopedro D, García-Herrera R, Lupo AR, Hernández E (2006) A climatology of Northern Hemisphere blocking. J Clim 19:10421063. doi:10.1175/JCLI3678.1

Barriopedro D, Fischer EM, Luterbacher J, Trigo RM, García-Herrera R (2011) The hot summer of 2010: redrawing the temperature record map of Europe. Science 332(6026):220-224. doi:10.1126/ science. 1201224

Bintanja R, Graversen RG, Hazeleger W (2011) Arctic winter warming amplified by the thermal inversion and consequent low infrared cooling to space. Nat Geosci Lett. doi:10.1038/NGEO1285
Blanchard-Wrigglesworth EK, Armour C, Bitz CM, DeWeaver E (2011a) Persistence and inherent predictability of Arctic sea ice in a GCM ensemble and observations. J Clim 24:231-250

Blanchard-Wrigglesworth E, Bitz CM, Holland MM (2011b) Influence of initial conditions and climate forcing on predicting Arctic sea ice. Geophys Res Lett. doi:10.1029/2011GL048807

Brown RD, Robinson DA (2011) Northern Hemisphere spring snow cover variability and change over 1922-2010 including an assessment of uncertainty. The Cryosphere 5:219-229. doi:10.5194/tc-5-219-2011

Chapman W, National Center for Atmospheric Research Staff (eds) (2013) The climate data guide: Walsh and Chapman Northern Hemisphere Sea Ice. Retrieved from https://climatedataguide. ucar.edu/climate-data/walsh-and-chapman-northern-hemispheresea-ice. Last modified Aug 202013

Chapman WL, Walsh JE (2007) Simulations of Arctic temperature and pressure by global coupled models. J Clim 20:609-632. doi:10.1175/JCLI4026.1

Charlton A, Lahoz W, O’Neill A, Massacand A (2004) Sensitivity of tropospheric forecasts to stratospheric initial conditions. Q J R Meterol Soc 130(660):1771-1792

Chevallier M, Salas-Mélia D (2012) The role of sea ice thickness distribution in the Arctic sea ice potential predictability: a diagnostic approach with a coupled GCM. J Clim 25:3025-3038

Chevallier M, Salas-Mélia D, Voldoire A, Deque M, Garric G (2013) Seasonal forecasts of the pan-Arctic sea ice extent using a GCM-based seasonal prediction system. J Clim 26(16):6092-6104

Christiansen B (2001) Downward propogation of zonal wind anomalies from the stratosphere to the troposphere: model and reanalysis. J Geophys Res 105:27307-27322

Cohen J, Barlow M, Kushner PJ, Saito K (2007) Stratosphere-troposphere coupling and links with Eurasian land surface variability. J Clim 20:5335-5343

Cohen J, Furtado JC, Barlow MA, Alexeev VA, Cherry JE (2012) Arctic warming, increasing snow cover and widespread boreal winter cooling. Environ Res Lett. doi:10.1088/1748-9326/7/1/014007

Comiso JC, Parkinson C, Gersten R, Stock L (2008) Accelerated decline in the Arctic sea ice cover. Geophys Res Lett. doi:10.102 9/2007GL031972

Dee DP, Uppala SM, Simmons AJ, Berrisford P, Poli P, Kobayashi S, Andrae U, Balmaseda MA, Balsamo G, Bauer P, Bechtold P, Beljaars ACM, van de Berg L, Bidlot J, Bormann N, Delsol C, Dragani R, Fuentes M, Geer AJ, Haimberger L, Healy SB, Hersbach H, Holm EV, Isaksen L, Kållberg P, Köhler M, Matricardi M, McNally AP, Monge-Sanz BM, Morcrette JJ, Park BK, Peubey C, de Rosnay P, Tavolato C, Thepaut JN, Vitart F (2011) The ERA-Interim reanalysis: configuration and performance of the data assimilation system. Q J R Meteorol Soc 137:553-597. doi:10.1002/qj.828

Deser C, Magnusdottir G, Saravanan R, Philips A (2004) The effects of North Atlantic SST and sea ice anomalies on the winter circulation in CCM3. Part II: direct and indirect components of the response. J Clim 17:2160-2176

Devasthale A, Sedlar J, Koenigk T, Fetzer EJ (2013) The thermodynamic state of the Arctic atmosphere observed by AIRS: comparisons during the record minimum sea ice extents of 2007 and 2012. Atmos Chem Pys 13:7441-7450. doi:10.5194/ acp-13-7441-2013

Eastwood S, Larsen KR, Lavergne T, Nielsen E, Tonboe R (2011) Global sea ice concentration reprocessing: product user manual, product OSI-409. Version 1:3

Francis JA, Chan W, Leathers DJ, Miller JR, Veron DE (2009) Winter Northern Hemisphere weather patterns remember summer Arctic sea-ice extent. Geophys Res Lett. doi:10.1029/200 9GL037274 
Garcia-Serrano J, Frankkignoul C (2014) High predictability of the winter Euro-Atlantic climate from cryospheric variability. Nat Geosci. doi:10.1038/NGEO2118

Graversen RG, Wang M (2009) Polar amplification in a coupled climate model with locked albedo. Clim Dyn 33:629-643. doi:10.1007/s00382-009-0535-6

Graversen RG, Mauritsen T, Tjernström T, Källén E, Svensson G (2008) Vertical structure of recent Arctic warming. Nature. doi:10.1038/nature06502

Guemas V, Blanchard-Wrigglesworth E, Chevallier M, Day JJ, Déqué M, Doblas-Reyes FJ, Fučkar N, Germe A, Hawkins E, Keeley S, Koenigk T, Salas-Mélia D, Tietsche S (2014) A review on Arctic sea ice predictability and prediction on seasonal-to-decadal timescales. Q J R Meteorol Soc. doi:10.1002/qj.2401

Holland MM, Serreze MC, Stroeve J (2010) The sea ice mass budget of the Arctic and its future change as simulated by coupled climate models. Clim Dyn 34:185-200. doi:10.1007/ s00382-008-0493-4

Honda M, Inoue J, Yamane S (2009) Influence of low Arctic sea-ice minima on anomalously cold Eurasian winters. Geophys Res Lett. doi:10.1029/2008GL037079

Hopsch S, Cohen J, Dethloff K (2012) Analysis of a link between fall Arctic sea ice concentration and atmospheric patterns in the following winter. Tellus A. doi:10.3402/tellusa.v64i0.18264

Inoue J, Masatake HE, Koutarou T (2012) The role of Barents Sea ice in the wintertime cyclone track and emergence of a warm-Arctic cold-Siberian anomaly. J Clim 25(7):2561-2568

Jaiser R, Dethloff K, Handorf D (2013) Stratospheric response to Arctic sea ice retreat and associated planetary wave propagation changes. Tellus A. doi:10.3402/tellusa.v65i0.19375

Jakobson E, Vihma T, Palo T, Jakobson L, Keernik H, Jaagus J (2012) Validation of atmospheric reanalyses over the central Arctic Ocean. Geophys Res Lett 39:L10802. doi:10.1029/201 2GL051591

Kalnay E, Kanamitsu M, Kistler R, Collins W, Deaven D et al (1996) The NCEP/NCAR 40-year reanalysis project. Bull Am Meterol Soc 77:434-471

Koenigk T, Brodeau L (2014) Ocean heat transport into the Arctic in the twentieth and twenty-first century in EC-Earth. Clim Dyn 42:3101-3120. doi:10.1007/s00382-013-1821-x

Koenigk T, Mikolajewicz U (2009) Seasonal to interannual climate predictability in mid and high northern latitudes in a global coupled model. Clim Dyn 32:783-798. doi:10.1007/ s00382-008-0419-1

Koenigk T, Mikolajewicz U, Haak H, Jungclaus J (2006) Variability of Fram Strait sea ice export: causes, impacts and feedbacks in a coupled climate model. Clim Dyn 26:17-34. doi:10.1007/ s00382-005-0060-1

Koenigk T, Mikolajewicz U, Jungclaus J, Kroll A (2009) Sea ice in the Barents Sea: seasonal to interannual variability and climate feedbacks in a global coupled model. Clim Dyn 32:1119-1138. doi:10.1007/s00382-008-0450-2

Koenigk T, Döscher R, Nikulin G (2011) Arctic future scenario experiments with a coupled regional climate model. Tellus 63A(1):6986. doi:10.1111/j.1600-0870.2010.00474.x

Koenigk T, Brodeau L, Graversen RG, Karlsson J, Svensson G, Tjernström M, Willen U, Wyser K (2013) Arctic climate change in 21 st century CMIP5 simulations with EC-Earth. Clim Dyn 40:2720-2742. doi:10.1007/s00382-012-1505-y

Kvamstö NG, Skeie P, Stephenson DB (2004) Large-scale impact of localized Labrador sea-ice changes on the North Atlantic Oscillation. Int J Climatol 24:603-612

Lau WKM, Kim KM (2012) The 2010 Pakistan flood and Russian heat wave: teleconnection of hydrometeorological extremes. J Hydrometeorol 13:392-403. doi:10.1175/JHM-D-11-016.1
Liptak J, Strong C (2014) The winter atmospheric response to sea ice anomalies in the Barents Sea. J Clim 27:914-924. doi:10.1175/ JCLI-D-13-00186.1

Liu Y, Key JR, Wang X (2008) The influence of changes in cloud cover on recent surface temperature trends in the Arctic. J Clim 21:705-715

Magnusdottir G, Deser C, Saravanan R (2004) The effects of North Atlantic SST and sea ice anomalies on the winter circulation in CCM3. Part I: main features and storm track characteristics of the response. J Clim 17(5):857-876

Massonnet F, Fichefet T, Goosse H, Bitz CM, Philippon-Berthier G, Holland MM, Barriat PY (2012) Constraining projections of summer Arctic sea ice. The Cryosphere 6:1383-1394. doi:10.5194/tcd-6-1383-2012

Nakamura H, Nakamura M, Anderson JL (1997) The role of high- and low-frequency dynamics in blocking formation. Mon Weather Rev 125:2074-2093

Notz D, Haumann FA, Haak H, Jungclaus J, Marotzke J (2013) Arctic sea-ice evolution as modeled by Max Planck Institute for Meteorology's Earth system model. J Adv Model Earth Syst 5:1-22. doi:10.1002/jame.20016

Orsolini YJ, Nikulin G (2006) A low ozone episode during the European heat wave of August 2003. Q J R Meteorol Soc 132:667-680

Overland JE, Wang M (2010) Large-scale atmospheric circulation changes are associated with the recent loss of Arctic sea ice. Tellus. doi:10.1111/j.1600-0870.2009.00421.x

Overland JE, Wood KR, Wang M (2011) Warm Arctic-cold continents: climate impacts of the newly open Arctic Sea. Polar Res. doi:10.3402/polar.v30i0.15787

Peings Y, Magnusdottir G (2014) Response of the wintertime Northern Hemisphere atmospheric circulation to current and projected arctic sea ice decline: a numerical study with CAM5. J Clim 27:244-264. doi:10.1175/JCLI-D-13-00272.1

Petoukhov V, Semenov VA (2010) A link between reduced BarentsKara sea ice and cold winter extremes over northern continents. J Geophys Res. doi:10.1029/2009JD013568

Richter-Menge J, Jeffries M (2011) The Arctic, in "state of the climate in 2010". Bull Am Meteorol Soc 92(6):S143-S160

Rinke A, Dethloff K, Dorn W, Handorf D, Moore JC (2013) Simulated Arctic atmospheric feedbacks associated with late summer sea ice anomalies. J Geophys Res Atm 118:7698-7714. doi:10.1002/jgrd.50584

Scaife AA, Arribas A, Blockley E, Brookshaw A, Clark RT, Dunstone N, Eade R, Fereday D, Folland CK, Gordon M, Hermanson L, Knight JR, Lea DJ, MacLachlan C, Maidens A, Martin M, Peterson AK, Smith D, Vellinga M, Wallace E, Waters J, Willams A (2014) Skillful long-range prediction of European and North American winters. Geophys Res Lett 41:2514-2519. doi:10.10 02/2014GL059637

Schär C, Vidale PL, Lüthi D, Frei C, Häberli C, Liniger M, Appenzeller C (2004) The role of increasing temperature variability in European summer heat waves. Nature 427:332-336

Screen JA, Simmonds I (2010a) Increasing fall-winter energy loss from the Arctic Ocean and its role in Arctic temperature amplification. Geophys Res Lett. doi:10.1029/2010GL044136

Screen JA, Simmonds I (2010b) The central role of diminishing sea ice in recent Arctic temperature amplification. Nature. doi:10.1038/nature09051

Serreze MC, Barrett AP, Stroeve JC, Kindig DN, Holland MM (2009) The emergence of surface-based Arctic amplification. The Cryosphere 3:11-19

Simonsen K, Haugan PM (1996) Heat budgets of the Arctic Mediterranean and sea surface heat flux parameterizations for the Nordic Seas. J Geophys Res 101:6553-6576 
Stocker T et al (2013) Climate change 2013: the physical science basis. Contribution of working group I to the fifth assessment report of the Intergovernmental Panel on Climate Change. Cambridge University Press, Cambridge

Tibaldi S, Molteni F (1990) On the operational predictability of blocking. Tellus 42A:343-365

Tietsche S, Day JJ, Guemas V, Hurlin WJ, Keeley SPE, Matei D, Msadek R, Collins M, Hawkins E (2014) Seasonal to interannual Arctic sea ice predictability in current global climate models. Geophys Res Lett 41(3):1035-1043. doi:10.1002/201 3GL058755

Uppala SM, Kållberg PW, Simmons AJ, Andrae U, Bechtold VD, Fiorino M, Gibson JK, Haesler J, Hernandez A, Kelly GA, Li X, Onogi K, Saarinen S, Sokka N, Allan RP, Andersson E, Arpe K, Balsamseda MA, Beljaars ACM, Van de Berg L, Bidlot J, Normann N, Caires S, Chevallier F, Dethof A, Dragosavac M,
Fisher M, Fuentes HagemannS, Holm E, Hoskins BJ, Isaksen L, Janssen PAEM, Jenne R, McNally AP, Mahfouf JF, Morcrette JJ, Rayner NA, Sauders RW, Simon P, Sterl A, Trenberth KE, Untch A, Vasiljevic D, Voterbo P, Wollen J (2005) The ERA-40 re-analysis. Q J R Meteorol Soc 131:2961-3012

Vavrus S, Holland MM, Jahn A, Bailey D, Blazey B (2012) 21stcentury Arctic climate change in CCSM4. J Clim 25:2696-2710. doi:10.1175/JCLI-D-11-00220.1

von Storch H, Zwiers FW (1999) Statistical analysis in climate research. Cambrige University Press, Cambridge

Wang M, Overland JE (2013) A sea ice free summer Arctic within 30 years: an update from CMIP5 models. Geophys Res Lett. doi: 10.1029/2012GL052868

Yang S, Christensen JH (2012) Arctic sea ice reduction and European cold winters in CMIP5 climate change experiments. Geophys Res Lett. doi:10.1029/2012GL053333 